\title{
Aging-Exacerbated Acute Axon and Myelin Injury Is Associated with Microglia-Derived Reactive Oxygen Species and Is Alleviated by the Generic Medication Indapamide
}

\author{
Nathan J. Michaels, ${ }^{1}$ Kennedy Lemmon, ${ }^{1}$ Jason R. Plemel, ${ }^{2}$ Samuel K. Jensen, ${ }^{1}{ }^{\circledR}$ Manoj K. Mishra, ${ }^{1}$ \\ Dennis Brown, ${ }^{1}$ Khalil S. Rawji, ${ }^{1}$ Marcus Koch, ${ }^{1}$ and ${ }^{\circledR}$ V. Wee Yong ${ }^{1}$ \\ ${ }^{1}$ Department of Clinical Neurosciences, Hotchkiss Brain Institute, University of Calgary, Calgary, Alberta T2N 4N1, Canada, and ${ }^{2}$ Department of \\ Medicine, Division of Neurology, Neuroscience and Mental Health Institute, University of Alberta, Edmonton, Alberta T6G 2R7, Canada
}

Age is a critical risk factor for many neurologic conditions, including progressive multiple sclerosis. Yet the mechanisms underlying the relationship are unknown. Using lysolecithin-induced demyelinating injury to the mouse spinal cord, we characterized the acute lesion and investigated the mechanisms of increased myelin and axon damage with age. We report exacerbated myelin and axon loss in middle-aged (8-10 months of age) compared with young ( 6 weeks of age) female C57BL/6 mice by 1-3 d of lesion evolution in the white matter. Transcriptomic analysis linked elevated injury to increased expression of $C y b b$, the gene encoding the catalytic subunit of NADPH oxidase gp91phox. Immunohistochemistry in male and female $\mathrm{Cx}_{3} \mathrm{Cr}{ }^{\mathrm{CreER} /+}$ :Rosa26 $6^{\mathrm{tdTom} /+}$ mice for gp91phox revealed that the upregulation in middle-aged animals occurred primarily in microglia and not infiltrated monocyte-derived macrophages. Activated NADPH oxidase generates reactive oxygen species and elevated oxidative damage was corroborated by higher malondialdehyde immunoreactivity in lesions from middle-aged compared with young mice. From a previously conducted screen for generic drugs with antioxidant properties, we selected the antihypertensive CNS-penetrant medication indapamide for investigation. We report that indapamide reduced superoxide derived from microglia cultures and that treatment of middle-aged mice with indapamide was associated with a decrease in age-exacerbated lipid peroxidation, demyelination and axon loss. In summary, age-exacerbated acute injury following lysolecithin administration is mediated in part by microglia NADPH oxidase activation, and this is alleviated by the CNS-penetrant antioxidant, indapamide.

Key words: antioxidant; axonal loss; demyelination; microglia; neurodegeneration; oxidative stress

Significance Statement

Age is associated with an increased risk for the development of several neurologic conditions including progressive multiple sclerosis, which is represented by substantial microglia activation. We demonstrate that in the lysolecithin demyelination model in young and middle-aged mice, the latter group developed greater acute axonal and myelin loss attributed to elevated oxidative stress through NADPH oxidase in lineage-traced microglia. We thus used a CNS-penetrant generic medication used in hypertension, indapamide, as we found it to have antioxidant properties in a previous drug screen. Following lysolecithin demyelination in middle-aged mice, indapamide treatment was associated with decreased oxidative stress and axon/myelin loss. We propose indapamide as a potential adjunctive therapy in aging-associated neurodegenerative conditions such as Alzheimer's disease and progressive multiple sclerosis.

Received May 7, 2020; revised Aug. 26, 2020; accepted Sep. 24, 2020.

Author contributions: N.J.M., J.R.P., S.K.J., K.S.R., M.K., and V.W.Y. designed research; N.J.M., K.L., and M.K.

M. performed research; N.J.M., K.L., J.R.P., S.K.J., M.K.M., D.B., K.S.R., and V.W.Y. analyzed data; N.J.M. and V.W.Y. wrote the paper.

The authors declare no competing financial interests.

This research was supported by operating grants from the Multiple Sclerosis Society of Canada (MSSC) and the Canadian Institutes of Health Research (CIHR). N.J.M., S.K.J., and K.S.R. were supported by predoctoral studentships, while J.R.P. and M.K.M. were supported by fellowships from MSSC. N.J.M. was also supported by an Eyes High University of Calgary studentship, while K.S.R. is a Canada Vanier Scholar and received additional support. J.R.P. was supported by fellowships from CIHR, T. Chen Fong, Australian Institute of Health \& Safety, and the Hotchkiss Brain Institute; as well as the Donna Joan Oxford award from the MS Society of Canada. K.L. received a summer studentship from the Alberta MS Network. V.W.Y. received support from the Canada Research Chair (Tier 1) program.

Correspondence should be addressed to V. Wee Yong at vyong@ucalgary.ca.

https://doi.org/10.1523/JNEUROSCI.1098-20.2020

Copyright $\odot 2020$ the authors

\section{Introduction}

The majority of patients with relapsing-remitting multiple sclerosis (MS) transition to secondary progressive MS. Approximately $15 \%$ of patients receive a diagnosis of primary progressive MS from disease onset (Reich et al., 2018). Age has been identified as an important contributor to the development of progression (Confavreux and Vukusic, 2006; Koch et al., 2009; Tutuncu et al., 2013) and is a likely link to axonal injury and loss (Bjartmar et al., 2003). Animal models of demyelination and traumatic spinal cord injury, for example, show increased axon and tissue damage with aging (Irvine and Blakemore, 2006; Siegenthaler et al., 2008; Hampton et al., 2012; von Leden et al., 2017). 
Exacerbated damage could be because of an altered immune response to injury. Microglia acquire deficiencies in phagocytosis and chemotaxis (Kotter et al., 2006; Njie et al., 2012; Ruckh et al., 2012; Rawji et al., 2016), become primed with age (Perry and Holmes, 2014), and are less able to adopt a regulatory phenotype (Miron et al., 2013; Fenn et al., 2014). Transcriptomic profiling of microglia isolated from aging animals shows upregulation of pathways involved with the production of reactive oxygen species (ROS) and nitric oxide species (O’Neil et al., 2018). ROS has the potential to be a potent mediator of exacerbated damage with age as the initial ROS-induced damage can self-propagate. NADPH oxidase is a major contributor of ROS in MS lesions (Fischer et al., 2012) and animal models of traumatic injury (Kumar et al., 2013; von Leden et al., 2017); in these studies, increased NADPH oxidase expression is found in microglia/ macrophages, and there is greater lesion size in traumatic injury models.

While microglia and macrophages can be reliably differentiated under homeostatic conditions, they become remarkably similar in morphology and by most markers in disease states (Keren-Shaul et al., 2017; Bennett et al., 2018; Plemel et al., 2020). The highly plastic nature of microglia and macrophages makes it challenging to specifically track and understand their respective roles after injury. In particular, the individual contribution of these cell types to ROS production and oxidative damage has not been ascertained. Differentiating the roles of microglia and macrophages in the acute stages of tissue injury has considerable implications for drug development. Mitigating microglia-specific damage, for instance, requires a drug to cross the blood-brain barrier (BBB). We previously screened compounds in vitro to identify orally available, well tolerated generic medications that target pathologic elements of progressive MS, such as the alleviation of oxidative stress (Faissner et al., 2017). We identified indapamide, a diuretic currently prescribed to treat hypertension and with capacity to cross the BBB (www.drugs.com), with antioxidant activity (Faissner et al., 2017), thus making it a candidate for testing in an in vivo model of myelin disruption and axon damage.

Age-associated differences in axon injury and tissue damage have been observed in both traumatic brain and spinal cord injury (Kumar et al., 2013; von Leden et al., 2017), but the relative role, if any, of microglia or macrophages in these processes is unclear. Furthermore, there are no reports on whether there are age-related differences in myelin pathology in an animal model commonly used to study MS. It is also uncertain whether differences in injury associated with age may be attributed to microglia or macrophages. Herein, we used lysolecithin-induced demyelination of the spinal cord in young and middle-aged mice to characterize the acute events of lesion formation and to elucidate the mechanisms of aging-enhanced white matter neurodegeneration. Our results highlight microglia, not infiltrating macrophages, as the primary expressors of NADPH oxidase in acute lesions of middle-aged mice. Moreover, we describe indapamide treatment in middle-aged mice to reduce demyelinated lesion volume and axonal loss, which are associated with less oxidative stress in the CNS white matter.

\section{Materials and Methods}

Mice. All experiments were performed in accordance with the Animal Care Committee at the University of Calgary. Mice were housed at the University of Calgary Animal Resource Center per regulations stated in the Canadian Council of Animal Care. Young (6 weeks of age) and middle-aged (8-10 months of age) wild-type mice used for in vivo lesion characterization and indapamide treatment experiments were purchased from Charles River; they were all on the C57BL/6 background. $\mathrm{Cx}_{3} \mathrm{Cr} 1^{\mathrm{CreER}}$ (JAX 021160) and Rosa26 ${ }^{\text {tdTom }}$ (tdTomato; JAX 007905) male and female mice on the C57BL/6 background were obtained from The Jackson Laboratory and crossed in the University of Calgary animal facility to generate $C x_{3} C r 1^{C r e E R /+}: R o s a 26^{\text {tdTom/ }+}$. For tissue culture microglia studies, pregnant mice on the CD1 background (to lower costs compared with C57BL/6 mice) were purchased from Charles River, and pups $1-3 \mathrm{~d}$ of age were used to derive cells. Thus, tissue culture studies used the CD1 strain while all in vivo experiments used the C57BL/6 strain.

Lysolecithin-induced demyelination. Experimental demyelination was induced using the toxin lysolecithin (Plemel et al., 2018). Animals were anesthetized with ketamine $(200 \mathrm{mg} / \mathrm{kg})$ and xylazine $(10 \mathrm{mg} / \mathrm{kg})$ injected intraperitoneally. The surgical site was shaved with a razor, the remaining hair was removed with $70 \%$ ethanol, and exposed skin was wiped with iodine. Immediately before the surgical procedure, the analgesic buprenorphine $(0.05 \mathrm{mg} / \mathrm{kg})$ was administered subcutaneously. The mouse was positioned in a stereotactic frame, an incision was made at the midline of the back, underlying muscle and adipose tissue was separated with retractors, and the vertebrae were exposed using blunt dissections. The connective tissue between T3 and T4 were removed with spring scissors, and the dura was cleared using lateral scrapes with a 30 gauge metal needle. The spinal cord was pierced at a $5^{\circ}$ angle lateral to the midline with a 34 gauge $12^{\circ}$ beveled needle attached to a $10 \mu$ syringe filled with $1 \%$ lysolecithin in PBS. The needle was lowered $1.3 \mathrm{~mm}$ from the dorsal surface of the spinal cord to inject into the ventrolateral white matter. Lysolecithin ( $0.5 \mu \mathrm{l}$ total; catalog \#L1381, Sigma-Aldrich) was injected into the white matter at a rate of $0.25 \mu \mathrm{l} / \mathrm{min}$ for $2 \mathrm{~min}$. The needle was left in place for $2 \mathrm{~min}$ to prevent backflow, then it was retracted and muscle and skin were sutured closed. Animals were kept in heated recovery chambers until they awoke and were placed into their cages.

Tissue processing. To study the early events of lesion formation, young and middle-aged animals were killed 4,24 , and $72 \mathrm{~h}$ after the injection of lysolecithin. Animals were transcardially perfused with 20 $\mathrm{ml}$ of room temperature PBS followed by perfusion with $20 \mathrm{ml}$ of icecold $4 \%$ paraformaldehyde in PBS. Spinal cords were isolated and postfixed in $4 \%$ paraformaldehyde overnight at $4^{\circ} \mathrm{C}$, cryoprotected in $30 \%$ sucrose at $4^{\circ} \mathrm{C}$ for at least $72 \mathrm{~h}$, and frozen in OCT (catalog \#25608-930, VWR) compound molds. Spinal cords were cut into $20 \mu \mathrm{m}$ coronal sections and kept at $-20^{\circ} \mathrm{C}$ until ready for histology.

Eriochrome cyanine. One set of spinal cord sections was exposed to eriochrome cyanine R (catalog \#32752, Sigma-Aldrich) to visualize myelin lipids. All outlined steps were performed at room temperature. Before staining, slides were air dried for $30 \mathrm{~min}$. Slides were then placed serially in Citrisolv (catalog \#22-143-975, Thermo Fisher Scientific), isopropanol, and graded ethanol solutions (100\%, 95\%, 90\%, 70\%, and 50\% water) for $1 \mathrm{~min}$ each. Following this rehydration step, slides were submerged in a $0.5 \%$ eriochrome cyanine $(\mathrm{w} / \mathrm{v})$ solution for $15 \mathrm{~min}$, washed with water for $1 \mathrm{~min}$, differentiated with $0.5 \%$ ammonium hydroxide (catalog \#320145, Sigma-Aldrich) for $10 \mathrm{~s}$, washed with water again, and submerged in $1 \%$ nuclear red $(\mathrm{w} / \mathrm{v})$ for $2 \mathrm{~min}$. Slides were once again washed with water for $1 \mathrm{~min}$ and dehydrated in graded ethanol solutions $(50 \%, 70 \%, 90 \%, 95 \%$, and $100 \%$ water), and placed in clearing agent for 1 min before being coverslipped with Acrytol mounting medium (cata$\log \# 3801700$, Leica Biosystems). Images were taken on an Olympus bright-field microscope with a $10 \times$ objective lens.

Immunohistochemistry. Slides were incubated for $60 \mathrm{~min}$ with blocking solution composed of PBS with $10 \%$ horse serum, $1 \%$ bovine serum albumin, $0.1 \%$ cold fish gelatin, $0.1 \%$ Triton X-100, and $0.05 \%$ Tween 20. Slides were then incubated overnight in a PBS antibody solution containing $1 \%$ bovine serum albumin, $0.1 \%$ cold fish gelatin, and $0.5 \%$ Triton X-100 with the following primary antibodies: mouse anti-SMI312 (1:1000; catalog \#837904, BioLegend), rat anti-MBP (myelin basic protein; 1:100; catalog \#ab7349, Abcam), rabbit anti-gp91phox (1:400; cata$\log \#$ ab80508, Abcam), rabbit anti-MDA (malondialdehyde adduct; 1:500; catalog \#ab6463, Abcam), rat anti-CD45 (1:400; catalog \#550539, BD Biosciences), rabbit anti-IBA1 (1:1000; catalog \#WDG5619, Wako), and mouse anti-GFAP (1:1000; catalog \#G3893, Sigma-Aldrich). Slides were then washed with PBS plus $0.05 \%$ Tween 20 and incubated with 
$\mathrm{F}\left(\mathrm{ab}^{\prime}\right)_{2}$ fragment secondary antibodies (Alexa Fluor 488, 594, and 647; 1:400; Jackson ImmunoResearch) for $1 \mathrm{~h}$. Images were collected on a confocal microscope (Fluoview Fv10i, Olympus) and analyzed with ImageJ (RRID:SCR_003070) software.

Myelin disruption volume. The method of quantitating myelin volume loss in lysolecithin lesion injury was previously used in Plemel et al., (2018). Twenty micrometer spinal cord sections were collected over a series of 10 sets of slides so that each section was $200 \mu \mathrm{m}$ away from its adjacent section on a given glass slide. Sections stained with eriochrome cyanine or with antibodies against MBP were imaged on a bright-field microscope or fluorescent microscope at $10 \times$ magnification. All sections possessing myelin disruption (indicated by pale blue or white regions after staining with eriochrome cyanine or disruption in cytoarchitecture with MBP staining) were imaged. ImageJ software was used to determine the area of myelin disruption in each section. The volume of demyelination per animal (Extended Data Fig. 1-1) was then estimated by summing the area of myelin disruption in all eriochrome cyanine-stained sections from that animal and then multiplying it by 200 to account for the distance between each section, as guided by other studies (Marcos et al., 2012). Although this did not involve unbiased stereological analysis, the same technique was applied across all animals to allow comparisons across groups.

Fluorescent image quantification. Color thresholds were used to isolate positive signal; masks were generated based on the threshold area; and the analyze particles function in ImageJ was used to determine the number, size, and mean intensity of selected areas. To determine the area of staining of gp91phox, the catalytic subunit of NADPH oxidase, the tdTom ${ }^{+}$signal was isolated using the color threshold function in ImageJ and a mask was generated. That mask was applied to the corresponding gp91phox channel and the area of the $\operatorname{tdTom}^{+}$signal that was also gp91phox positive was calculated. For determining the amount of gp91phox in $\mathrm{CD}_{4} 5^{+}$cells, the tdTom-mask was applied to the CD45 channel and subtracted from the image removing $\operatorname{tdTom}^{+} / \mathrm{CD} 45^{+}$cells from the image. The $\mathrm{CD}_{4} 5^{+}$signal was then isolated using the color threshold tool, a mask was generated, and that mask was applied to the corresponding gp91phox channel. The area of $\mathrm{CD} 45^{+}$signal that was also gp91phox ${ }^{+}$could then be calculated.

Laser capture microdissection and RNA sequencing. Six-week-old and 8- to 10-month-old mice were perfused $72 \mathrm{~h}$ after lysolecithin injection with RNA- and DNA-free PBS, and spinal cords were isolated and snap frozen in a mixture of dry ice and 2-methyl-butane. Spinal cords were sectioned coronally at $20 \mu \mathrm{m}$ and collected on nuclease-free PENmembrane slides (catalog \#LCM0522, Zeiss), fixed in 70\% ethanol (v/v), stained with $1 \%$ Cresyl Violet (w/v), and dehydrated sequentially with $70 \%$ and $100 \%$ ethanol. Laser-capture microdissection of lesioned and spatially analogous naive white matter was performed on the PALM MicroBeam (Zeiss), and total RNA was isolated using the RNeasy MiniKit (catalog \#74104, Qiagen). RNA quality was determined using the Agilent 2200 TapeStation, and only samples with an RNA integrity number $>8$ were used for sequencing. RNA was amplified with the REPLI-g protocol before sequencing on the Illumina NextSeq500 platform. Sequencing reads were assessed for quality using the FastQC (version 0.11.4) software, were mapped to the genome (GRCm38, Ensembl) using TopHat (version 2.0.10) with bowtie (version 1.1.2) as an internal aligner, and raw read counts were calculated using featureCounts at the gene level. Raw counts were then loaded into R (version 3.3.2), and exploratory analysis and sample clustering were conducted using normalized and variance stabilized data. Differential expression analysis was performed using the DESeq2 Bioconductor package, and the effect that age had on injury was determined. Significance cutoffs were set at $p<0.05$. Pathway analysis was performed with Ingenuity Pathway Analysis (IPA; Qiagen Bioinformatics) software. Pathways were considered significantly altered at $p<0.05$. Transcriptomic data are available on the National Center for Biotechnology Information database with the accession code GSE129000.

Microglia-enriched cultures. All murine in vitro experiments were performed in accordance with ethical animal care guidelines by the Animal Care Committee at the University of Calgary. Our microglia isolation protocol is adapted from the study by Milner and Ffrench-
Constant (1994). Pups age postnatal day 0 (P0) to P3 of mixed sex were killed via decapitation, and the brains were removed from the skull and immediately placed in sterile, ice-cold DMEM (catalog \#11960069, Thermo Fisher Scientific). Both cortices were isolated from the hindbrain and meninges overlying the cortex were removed with fine forceps. Once all cortices were isolated from all pups in the litter, they were pooled and mechanically minced with a scalpel. Tissue was collected in a $50 \mathrm{ml}$ centrifuge tube and vortexed to destroy ramified neurons and larger cell types. Tissue was triturated with a $1 \mathrm{ml}$ micropipette and passed sequentially through 80 and $11 \mu \mathrm{m}$ sieves to remove debris and remaining meningeal tissue. Cells were then seeded in T75 flasks (one per pup) coated with poly-D-lysine (catalog \#A3890401, Thermo Fisher Scientific) containing $\sim 10 \mathrm{ml}$ of medium. The medium contained DMEM, $1 \%$ L-glutamine (catalog \#25030164, Thermo Fisher Scientific), 1\% penicillin/ streptomycin (catalog \#15140122, Thermo Fisher Scientific), 1\% sodium pyruvate (catalog \#11360070, Thermo Fisher Scientific), 1\% MEM nonessential amino acids (catalog \#11140076, Thermo Fisher Scientific), and $10 \%$ fetal bovine serum heat inactivated (catalog \#10438034, Thermo Fisher Scientific). Flasks containing cells were placed in a $37^{\circ} \mathrm{C}$ tissue culture incubator at $5 \% \mathrm{CO}_{2}$ for $7-10 \mathrm{~d}$ until it reached confluence. Media was changed every $3 \mathrm{~d}$. To isolate microglia from the underlying bed of astrocytes, flasks were shaken at $250 \mathrm{rpm}$ for $20 \mathrm{~min}$. Medium containing free-floating cells was collected in a $50 \mathrm{ml}$ tube and centrifuged. Cells were resuspended in medium containing DMEM, 1\% L-glutamine, $1 \%$ penicillin/streptomycin, $1 \%$ sodium pyruvate, 1\% MEM nonessential amino acids, and 1\% N1 supplement (catalog \#N6530-5ML, SigmaAldrich).

Preparation of indapamide for in vitro experiments. Twenty milligrams of indapamide [ $\mathrm{N}$-(4-chloro-3-sulfamoylbenazmido)-2-methylinodoline; catalog \#I1887, Sigma-Aldrich] was dissolved in 100\% DMSO (catalog \#276855, Sigma-Aldrich) to make a $55 \mathrm{~mm}$ stock solution. The stock solution was filtered and frozen at $-20^{\circ} \mathrm{C}$. Dilutions $(1,10,20,40$, and $80 \mu \mathrm{M}$ ) were made from this stock.

Extracellular superoxide assay. Extracellular superoxide was determined using a well established protocol based on cytochrome $c$ oxidation (Badger, 1986). Microglia were seeded in 96-well plates at a density of 50,000 cells/well. Cells were incubated for $1 \mathrm{~h}$ with indapamide or DMSO. Media were removed, cells were washed with phenol red free HBSS (catalog \#14175095, Sigma-Aldrich), and cytochrome $c(160 \mu \mathrm{M}$; catalog \#9007-43-6, Sigma-Aldrich) diluted in phenol red free HBSS was added to the wells. Indapamide or DMSO was readded to wells, and lipopolysaccharide (LPS; $100 \mathrm{ng} / \mathrm{ml}$; catalog \#L2630, Sigma-Aldrich) was added. The negative control condition contained the LPS and superoxide dismutase (SOD; 600 U/well; catalog \#S7571, Sigma-Aldrich). Following an additional $1 \mathrm{~h}$ of incubation with inhibitors and activators added, absorbance was read at $550 \mathrm{~nm}$ using the activator plus SOD condition as the blank.

Cell viability assay. Plated microglia were treated with indapamide or DMSO and incubated for $1 \mathrm{~h}$, LPS $(100 \mathrm{ng} / \mathrm{ml})$ was added, and cells were incubated for an additional $1 \mathrm{~h}$. Ten minutes before imaging, a mixture containing DAPI (1:10), Calcein AM (1:100), and propidium iodide (1:10) was added to all wells. Cells were imaged using the ImageXpress (Molecular Devices).

Tamoxifen injection. Tamoxifen (catalog \#T-5648, Sigma-Aldrich) was given to $C x_{3} c r 1^{C r e E R /+}: R o s a 26^{t d T o m /+}$ mice as a solution in corn oil (catalog \#C-8267, Sigma-Aldrich). Animals to be demyelinated in the young ( 6 weeks old) or middle-aged (8-10 months old) group both received their tamoxifen at $\sim 2$ weeks of age. Each mouse received three intraperitoneal doses of $1 \mathrm{mg}$ of tamoxifen with a separation of $24 \mathrm{~h}$ between doses. As we described previously (Plemel et al., 2020), microglia, being self-renewing, are permanently labeled with tdTom after tamoxifen treatment while monocytes (and hence macrophages when they invaded tissues) are regularly generated from bone marrow stem cells and are negative for tdTom label by 4 weeks after tamoxifen.

In vivo indapamide treatment. Indapamide is commonly prescribed at $2.5 \mathrm{mg}$ doses in humans to treat hypertension (www.drugs.com). Translation of doses from one species to another is not a simple conversion based on weight, but on surface area of the body, liver metabolism, and other pharmacodynamic and pharmacokinetic features of drug in 
A

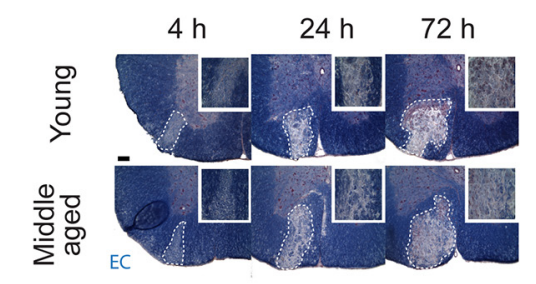

B

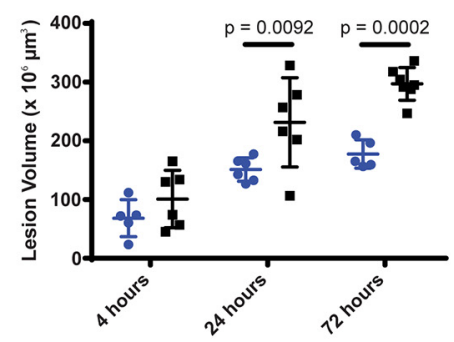

C

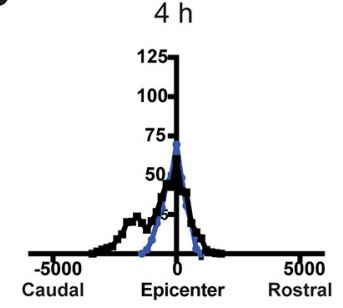

$\mathbf{F}$

D

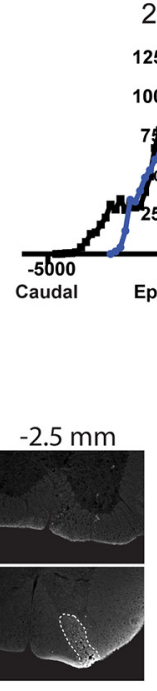

$24 \mathrm{~h}$

E

$72 \mathrm{~h}$

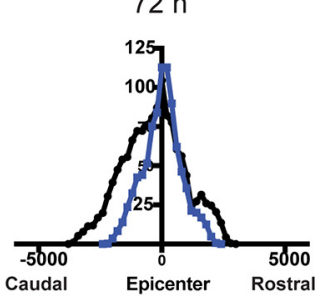

G

- Young

- Middle-aged
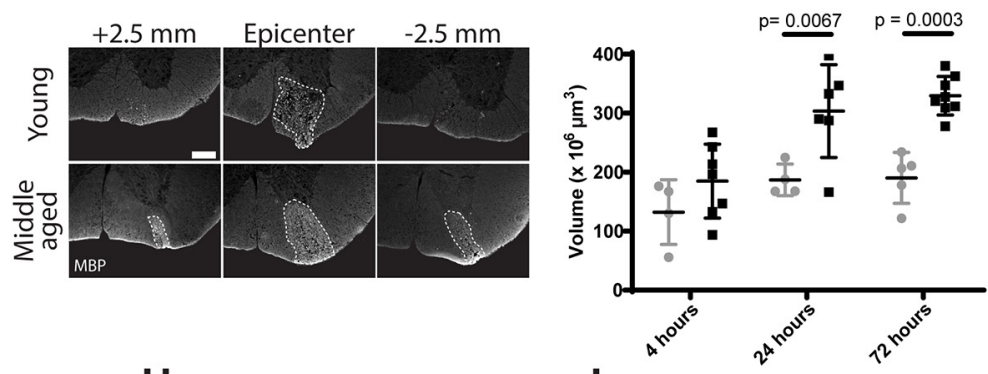

H
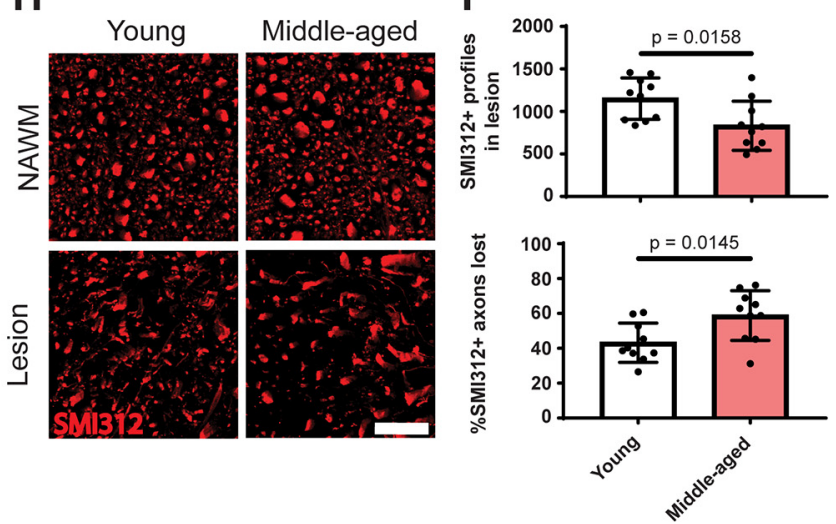

Figure 1. Aging is associated with exacerbated myelin disruption and axon loss in $C 57 \mathrm{BL} / 6$ mice. $\boldsymbol{A}$, Representative images of spinal cord coronal sections stained with eriochrome cyanine (EC) 4, 24, and $72 \mathrm{~h}$ following lysolecithin injection. Lipid-rich components of the tissue appear blue. Staining of areas with myelin disruption diminishes as myelin content decreases after exposure to lysolecithin. Scale bar, $200 \mu \mathrm{m}$. $\boldsymbol{B}$, The volume of lesion, quantitated as depicted in Extended Data Figure 1-1, is significantly greater in middle-aged animals 24 and $72 \mathrm{~h}$ after the injection of lysolecithin. Each dot represents one animal. $C-E$, Lesions in middle-aged animals extend further along the rostral-caudal axis ( $4 h, p=0.5263 ; 24 h, p=0.0092 ; 72 h, p=0.0002)$. The distribution represents the mean myelin disruption in each section rostral and caudal to the epicenter. Young $4 \mathrm{~h}(n=5)$; Young $24 \mathrm{~h}(n=6)$; Young $72 \mathrm{~h}(n=5)$; Middle-aged $4 \mathrm{~h}(n=6)$; Middle-aged $24 \mathrm{~h}(n=6)$; Middle-aged $72 \mathrm{~h}(n=8) . \quad F$, Representative micrographs of coronal spinal cord sections stained for MBP at the epicenter of the lesion and \pm 2.5 $\mathrm{mm}$ rostral or caudal to the epicenter. Scale bar, $200 \mu \mathrm{m}$. $\mathbf{G}$, Lesion volume is significantly greater in middle-aged animals 24 and $72 \mathrm{~h}$ after the injection of lysolecithin ( $4 \mathrm{~h}, p=0.3415 ; 24 \mathrm{~h}, p=0.0067 ; 72 \mathrm{~h}, p=0.0003$ ). The analysis with MBP reproduces the results obtained with eriochrome cyanine. $\boldsymbol{H}$, Representative micrographs of young and middle-aged spinal cord coronal sections in the lesion or in contralateral normal-appearing white matter. Tissue was stained with antibodies against SMI312 to visualize phosphorylated and nonphosphorylated neurofilaments. Scale bar, $25 \mu \mathrm{m} . \mathrm{I}, \mathrm{SMI} 312^{+}$profiles were counted in the center of the lesion and in the contralateral normal- that species; a 0.08 conversion factor from a $20 \mathrm{~g}$ mouse to a $60 \mathrm{~kg}$ human is a rough guide, but this is also drug specific (Nair and Jacob, 2016). Thus, to ascertain the dose to be used in mice to ameliorate oxidative stress within the CNS, we searched but did not find applicable antioxidant literature. Indeed, we found only two citations in PubMed on the effective doses of indapamide for any outcomes in mice. The first study reported that indapamide at $3 \mathrm{mg} / \mathrm{kg}$ did not alter the threshold for maximal electroconvulsions by itself, but enhanced the anticonvulsant action of some antiepileptic drugs (Kozinska et al., 2009). The second study (Zaluska et al., 2018) reported that the dose of indapamide that increased the threshold for electroconvulsions in mice by $20 \%$ compared with controls was $3.9 \mathrm{mg} / \mathrm{kg}$. Reasoning that the lysolecithin-induced lesion in the current study was rapidly incurred and substantial (Plemel et al., 2018), and that indapamide would have to cross the blood-spinal cord barrier and be maintained at high concentrations, we chose a proof of principle dose of $20 \mathrm{mg} / \mathrm{kg}$.

Twenty $\mathrm{mg}$ of indapamide (catalog \#I1887, SigmaAldrich) was dissolved in 100\% DMSO to make a $20 \mathrm{mg} / \mathrm{ml}$ stock solution. The stock was diluted in sterile PBS to create a working solution of $2 \mathrm{mg} / \mathrm{ml}$. Middle-aged mice were injected intraperitoneally with $300 \mu \mathrm{l}$ of $2 \mathrm{mg} / \mathrm{ml}$ (10\% DMSO) indapamide solution to attain a concentration of $20 \mathrm{mg} / \mathrm{kg}$ per dose per animal. A PBS control was used for the $3 \mathrm{~d}$ treatment paradigm, while a $10 \%$ DMSO vehicle control was used for the $7 \mathrm{~d}$ treatment paradigm.

Experimental design and statistical analysis. For in vivo experiments, mice were randomly allocated to their respective groups. Sample size was determined by previous studies using the lysolecithin model with several outcome measures. All animal experiments had a minimum of four mice per group. Multiple sections per animal were evaluated, and the results from each mouse were considered as $n$ of 1 .

All statistical analyses were performed using GraphPad Prism 6.0 software. For experiments in which two groups were compared, a two-tailed $t$ test was performed for parametric data unless otherwise stated (the latter when we were affirming whether the data would be in a particular direction). For experiments in which there were more than two groups with one independent variable, a one-way ANOVA was conducted. Where there were more than two groups with two independent variables, a two-way ANOVA was used. Post-ANOVA multiple comparisons were performed with Dunnett's or Sidak's multiple-comparisons test. Graphs display the mean and SD.

\section{Results}

Aging is associated with exacerbated myelin disruption and axon loss

Increased lesion size in aging animals has been observed in models of traumatic brain injury

appearing white matter. Data are presented as an absolute number of $\mathrm{SMI}_{312} 2^{+}$profiles $(p=0.0158)$ found in the lesion and as a proportion of axons lost relative to normal appearing white matter (NAWM) contralateral control $(p=0.0145)$. Middle-aged animals display significantly greater axon loss $72 \mathrm{~h}$ following the injection of lysolecithin. Each dot represents one animal. Student's two-tailed $t$ test or two-way ANOVA with Sidak's test for multiple comparisons; data are presented as the mean \pm SD. 
and spinal cord injury (Kumar et al., 2013; von Leden et al., 2017). Myelin disruption at acute time points after white matter insult, however, has not been characterized as a function of age. We first sought to investigate this by injecting lysolecithin, a lipid-disrupting agent cleared from tissue within hours of the injection (Plemel et al., 2018), into the ventrolateral spinal cord white matter of middle-aged (8-10 months old) or young (6 weeks) C57BL/6 mice. Animals were killed 4, 24, and $72 \mathrm{~h}$ after lysolecithin injection, and spinal cord sections were stained with eriochrome cyanine to detect myelin (Fig. 1A). Young and middle-aged mice did not display any differences in the area of the lesion of a single slice taken at its epicenter (Extended Data Fig. 1-1), which was defined as the tissue section containing the greatest area of myelin disruption. Young and middle-aged animals did differ, however, in the volume of myelin disruption when multiple sections encompassing the entire lesion were collated (Fig. 1B); middle-aged animals displayed significantly more myelin disruption volume extending rostral and caudal to the epicenter at 24 and $72 \mathrm{~h}$ after the injection of lysolecithin (Fig. $1 C-E)$. We corroborated these myelin disruption findings with immunohistochemistry for MBP (Fig. $1 F, G$ ).

Increased axon loss in aging animals 4 weeks following focal experimental autoimmune encephalomyelitis (EAE) and 7 weeks after cuprizone-mediated demyelination have been reported (Irvine and Blakemore, 2006; Hampton et al., 2012). We determined whether axonal loss is exaggerated in aging C57BL/6 mice within $72 \mathrm{~h}$ of a demyelinating insult. We sampled the day 3 time point where the axonal profiles could be reliably ascertained. Staining with the pan-axonal neurofilament marker SMI312 revealed fewer lesional axons in both young and middleaged mice compared with normal-appearing white matter in the contralateral uninjected area (Fig. $1 H$ ). Quantitation of SMI $312^{+}$ profiles within the lesion showed fewer remaining axons in middle-aged versus young mice, either as absolute counts or expressed as the proportion of axons lost in each animal relative to an internal control (Fig. 1I). Together, these data establish that rapid myelin disruption and axonal loss after lysolecithin injury is exacerbated in middle-aged animals compared with their younger counterparts.

\section{Increased $C y b b$ transcripts and associated pathways in middle-aged white matter lesions}

We explored gene expression changes associated with age-exacerbated white matter injury in middle-aged animals by sequencing lesion mRNA. Injured or naive white matter was isolated from the ventrolateral spinal cord of young and middle-aged C57BL/6 mice using laser capture microdissection. In injured animals, tissue was dissected $72 \mathrm{~h}$ after lysolecithin injection. Differential expression analysis (accession codes GSE129000) revealed 447 genes associated with age that influenced injury. We focused our analysis on genes with fold changes $>1.5$ and $p$ values $<0.01$ (Fig. $2 A$ ). These cutoffs left us with 50 genes, which are listed in Extended Data Fig. 2-1. The gene expression dataset was also subjected to IPA to identify biological pathways that were altered. We cross-referenced significantly upregulated and downregulated canonical biological pathways with our 50 genes of interest. Six genes of the 50 that we identified were involved in significantly altered biological pathways ( $C y b b, L b p, C d 74$, $M m p 12$, Clec7A, and Ccnb1; Fig. 2B), and their expression values are displayed in Figure 2C. Clec7a had the highest expression values in middle-aged injured tissue. $C y b b$ was also significantly elevated in middle-aged injured tissue compared with young (Fig. $2 C$ ), and it was associated with several significantly altered

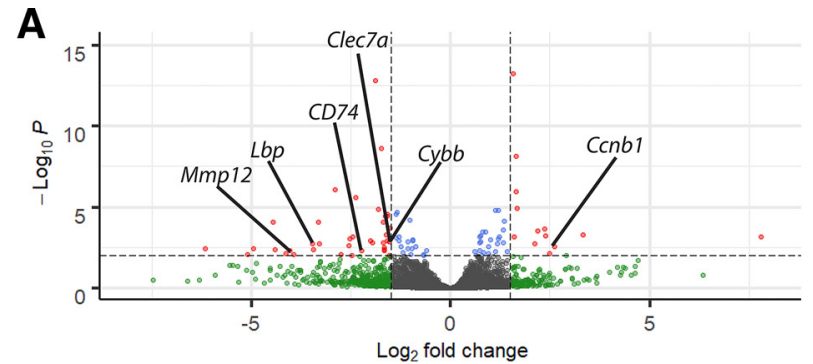

NS Log(base2)fold-change $>|1.5| \bigcirc$ Adjusted $p$-value $>0.01$ Log(base2)fold-change $>|1.5| \&$ Adjusted $p$-value $>0.01$

B Pathway

z-score

\begin{tabular}{|c|c|c|}
\hline Cybb & $\begin{array}{l}\text { Leukocyte extravasation signaling } \\
\text { IL-8 signaling } \\
\text { Production of ROS and RNS }\end{array}$ & $\begin{array}{l}2.324 \\
2.065 \\
1.604\end{array}$ \\
\hline$b p$ & $\begin{array}{l}\text { Toll-like receptor signaling } \\
\text { IL-6 signaling } \\
\text { LXR/RXR activation }\end{array}$ & $\begin{array}{l}2.121 \\
1.508 \\
-1.604\end{array}$ \\
\hline$d 74$ & $\begin{array}{l}\text { MIF regulation of innate immunity } \\
\text { MIF-mediated glucocorticoid regulation }\end{array}$ & $\begin{array}{l}2.449 \\
2\end{array}$ \\
\hline Mmp12 & Leukocyte extravasation signaling & 2.324 \\
\hline Clec $7 a$ & $\begin{array}{l}\text { Role of pattern recognition receptors in } \\
\text { recognition of bacteria and viruses }\end{array}$ & 1.897 \\
\hline Canbl & $\begin{array}{l}\text { Cell cycle: G2/M DNA damage checkpoint } \\
\text { regulation }\end{array}$ & 2.236 \\
\hline
\end{tabular}

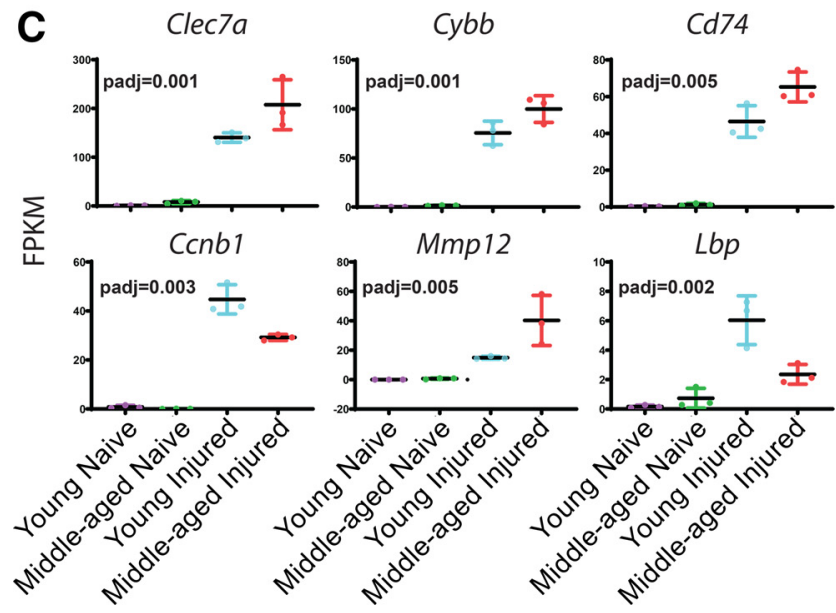

Figure 2. Increased Cybb transcripts and associated pathways in middle-aged C57BL/6 white matter lesions. $\boldsymbol{A}$, Genes were plotted based on fold change and $p$ value. Cutoffs of an adjusted $p$ value $<0.01$ or $\log 2$ (fold change) $>|1.5|$ were used to identify genes of interest, which are displayed as red dots. Fifty genes of interest were found and are listed in Extended Data Figure 2-1. B , Ingenuity Pathway Analysis highlights canonical biological pathways significantly altered with injury in middle-aged animals relative to young animals. of the 50 genes of interest, 6 played roles in these biological pathways. The $z$ score of the biological pathway is an indicator of how highly the pathway is upregulated or downregulated. All pathways shown are significantly altered with a $p$ value $<0.05$. C, Raw FPKM (fragments per kilobase of exon model per million reads mapped) levels of six genes of interest overlapping with significantly altered biological pathways. The $p$ value refers to the effect that age had on fold changes associated with injury.

biological pathways [leukocyte extravasation signaling, IL-8 signaling, and production of ROS and reactive nitrogen species (RNS); Fig. 2B]. We thus selected $C y b b$ for further analysis, recognizing that the other five candidates ( $L b p, C d 74, M m p 12$, $C l e c 7 A$, and $C c n b 1$ ) are valid targets for future studies. 

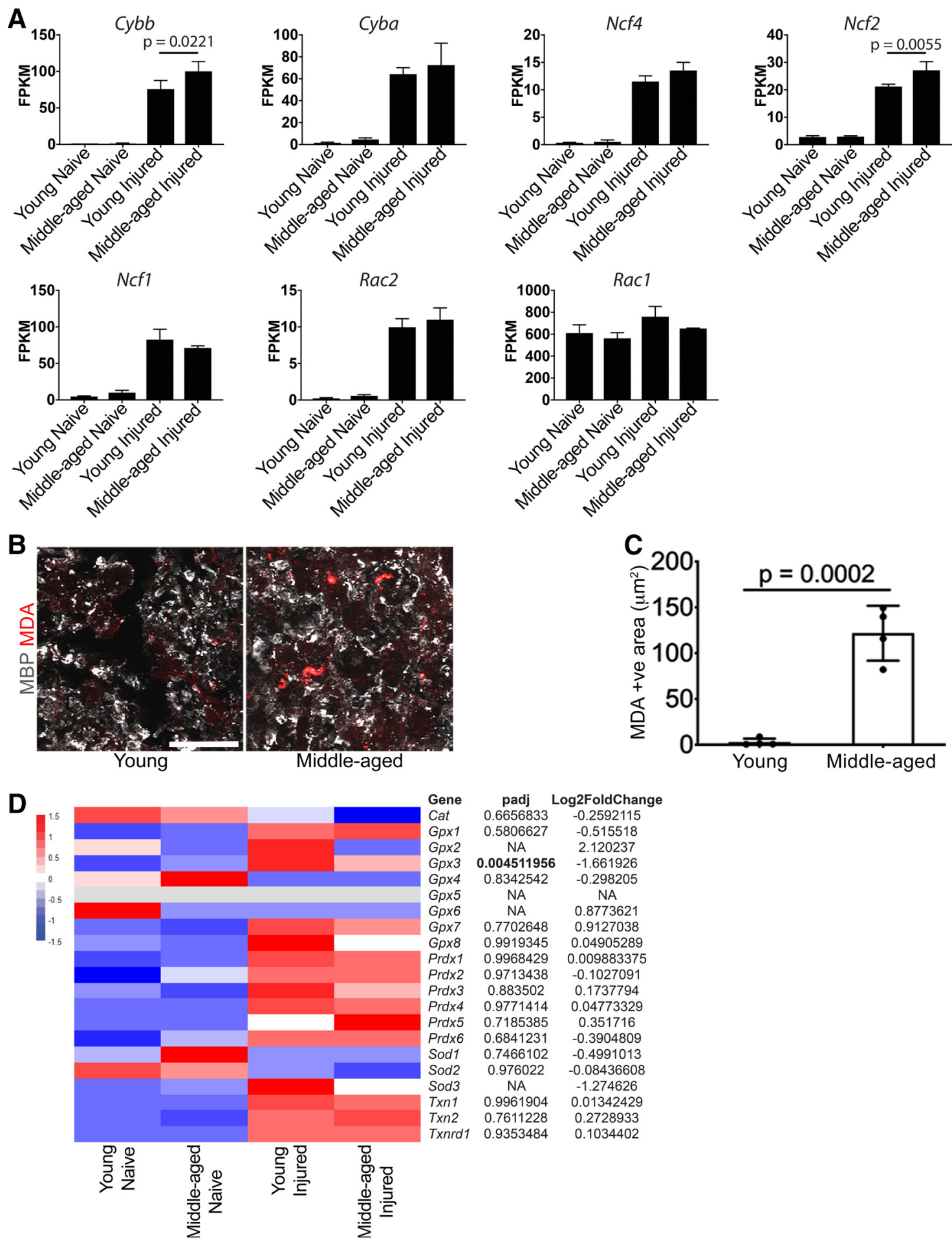

Figure 3. Expression of transcripts for NADPH oxidase subunits and other antioxidant enzymes, and increased lipid peroxidation, in middle-aged CNS white matter lesions. $\boldsymbol{A}$, Raw FPKM (fragments per kilobase of exon model per million reads mapped) levels of NADPH oxidase subunits. (ybb and Ncf2 are more highly expressed in middle-aged lesions. $\boldsymbol{B}$, Representative micrographs of coronal spinal cord sections stained with antibodies against MDA and MBP. There is noticeable spatial overlap between the two stains. Scale bar, $25 \mu \mathrm{m}$. $C$, Quantification of MDA in middle-aged and young animals suggests oxidative stress is greater in middle-aged animals $(p=0.0002)$. $\boldsymbol{D}$, Heatmap of endogenous antioxidant enzyme expression. All animals are on the C57BL/6 wild-type strain.

Increased lipid peroxidation and gp91phox expression in middle-aged CNS white matter lesions

$C y b b$ is the gene encoding gp91phox, which is part of the sixsubunit enzyme NADPH oxidase. The enzyme complex produces the superoxide anion. In addition to $C y b b$, we found that $N c f 2$, but not other NADPH oxidase subunits, was higher in middle-aged compared with young lesions (Fig. 3A). ROS and RNS production was one of the significantly upregulated canonical biological pathways identified with the IPA software (Fig. $2 B$ ); moreover, elevated oxidative stress has been identified in MS lesions (Haider et al., 2011; Fischer et al., 2012) and in animal models of traumatic CNS injury in association with age (Kumar 
A

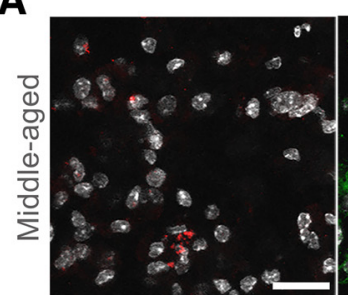

DAPI MDA

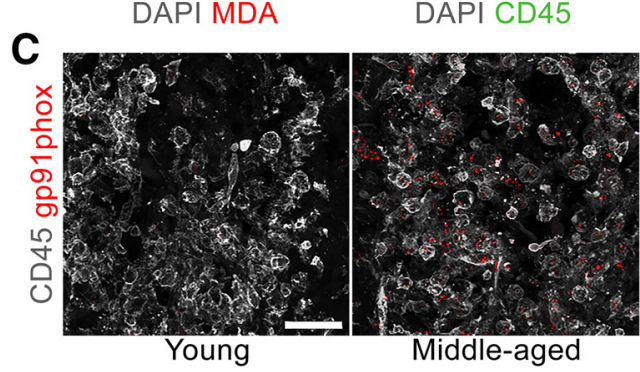

D

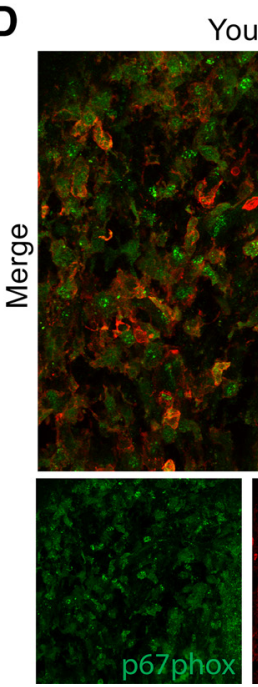

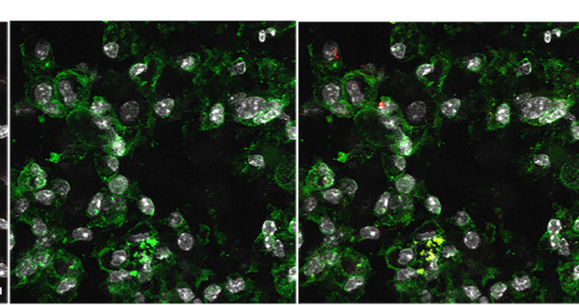

Merge
B

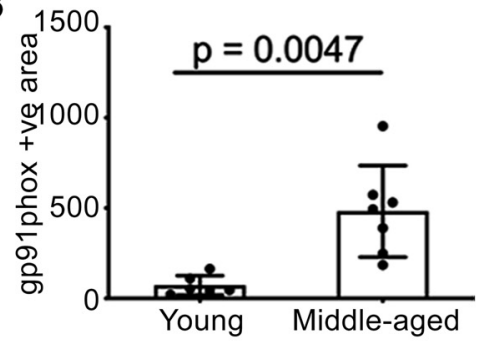

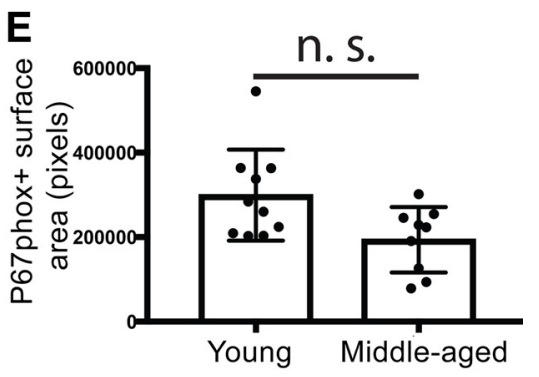

Figure 4. Correspondence of MDA in CD45 ${ }^{+}$cells, and elevation of gp91phox in middle-aged tissue. $A$, Spinal cord sections stained with antibodies against CD45 and MDA. MDA appears spatially associated with CD45 on the surface and within $\mathrm{CD}_{4} 5^{+}$cells. B, Quantification of gp91phox ${ }^{+}$area displays a higher value in middle-aged mice. $C$, Coronal spinal cord sections stained with antibodies against gp91phox and CD45. D. Coronal spinal cord sections stained with antibodies against NCF2 and CD45. $E$, Quantification of NCF2 ${ }^{+}$area displays no significant difference between young and middle-aged mice. Each dot represents one animal (Student's two-tailed $t$ test); data are presented as the mean \pm SD; all images are taken within lesioned white matter of wild-type C57BL/6 mice. Scale bar, $50 \mu$ m. n.s., not significant.

et al., 2013; von Leden et al., 2017). We therefore sought to determine whether there was a difference in oxidative stress between young and middle-aged lesions at acute time points after lysolecithin-induced demyelination. To do this, we used malondialdehyde, an immunohistochemical marker of lipid peroxidation (Haider et al., 2011). The more ROS present in the tissue, the more lipid peroxidation will take place, and the more malondialdehyde protein adducts will be formed. Staining for malondialdehyde in young and middle-aged C57BL/6 spinal cord tissue $72 \mathrm{~h}$ after the injection of lysolecithin revealed an $\sim 100$-fold increase in malondialdehyde immunoreactivity in the lesions of middleaged mice (Fig. $3 B, C$ ). The expression of endogenous antioxidant enzymes, except glutathione peroxidase 3 (Gpx3), was not significantly different between young and middle-aged animals (Fig. $3 D$ ). Elevated oxidative stress in middle-aged tissue is likely a result of increased ROS production without a concomitant increase in antioxidant machinery.

Having identified elevated lipid peroxidation in spinal cord lesions of middle-aged mice, we determined the cell types that it was most prominently associated with. Staining for myelin (MBP), leukocytes (CD45), astrocytes (GFAP), and axons (SMI312), we found malondialdehyde immunoreactivity in the closest spatial association with MBP (Fig. 3B) and $\mathrm{CD} 45^{+}$leukocytes, both within the latter and localized to their cell membrane (Fig. 4A).

Elevated expression of NADPH oxidase subunits in association with microglia/macrophage has been observed in MS lesions, in animal models of traumatic brain and spinal cord injury, and in EAE (Kumar et al., 2013; Di Filippo et al., 2016; von Leden et al., 2017). We observed increased expression of transcripts encoding certain NADPH oxidase subunits and aimed to corroborate these observations at the protein level using immunohistochemistry. Since $\mathrm{CD} 45^{+}$leukocytes spatially associated with malondialdehyde and microglia/macrophages are the primary expressors of NADPH oxidase in MS lesions and other models of injury, we costained C57BL/6 spinal cord tissue sections for gp91phox and CD45. We observed abundant gp91phox immunoreactivity within $\mathrm{CD}_{4} 5^{+}$cells, suggesting that these leukocytes are the predominant cells expressing gp91phox in middle-aged lysolecithin lesions $72 \mathrm{~h}$ after lysolecithin (Fig. 4C). In line with the transcript changes, comparing between the age groups revealed increased 
A

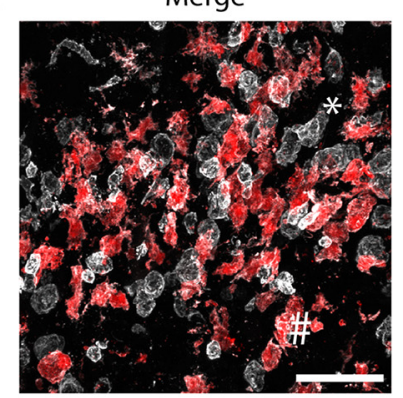

TdTomato
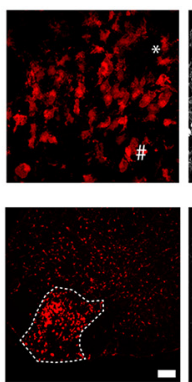

CD45
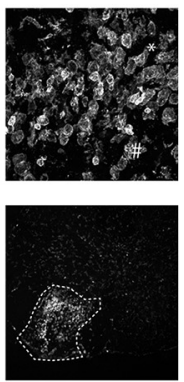

DAPI

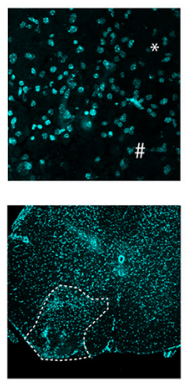

B
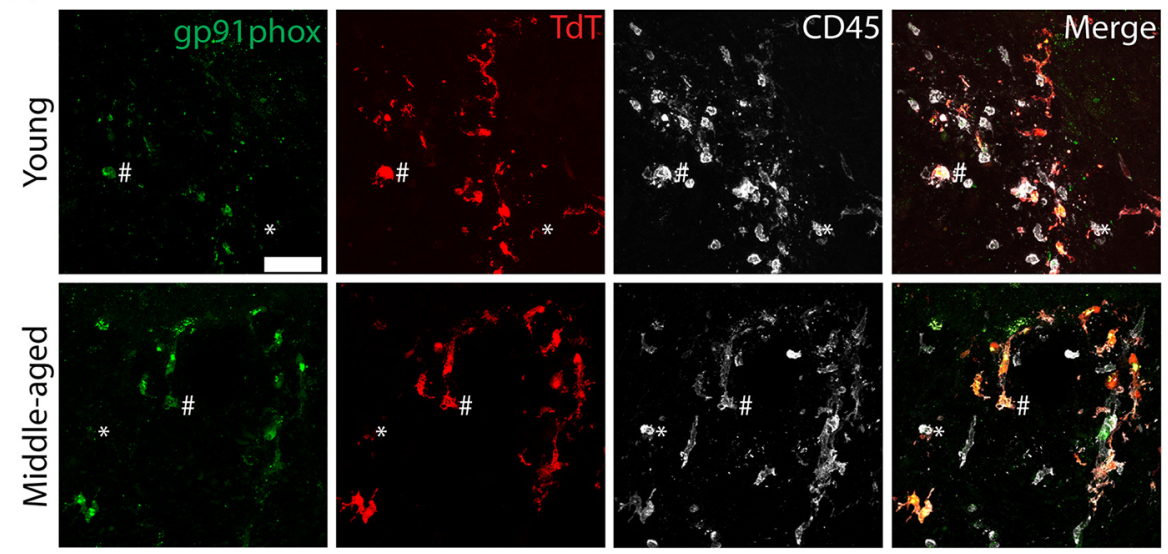

C

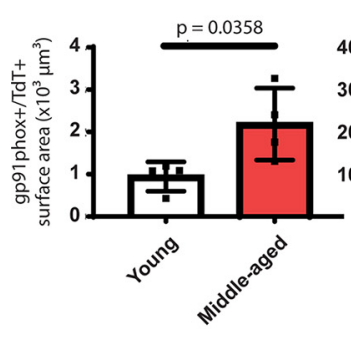

$24 \mathrm{~h}$

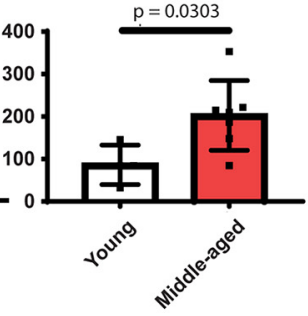

$72 \mathrm{~h}$

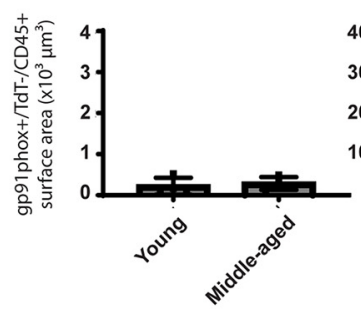

$24 \mathrm{~h}$

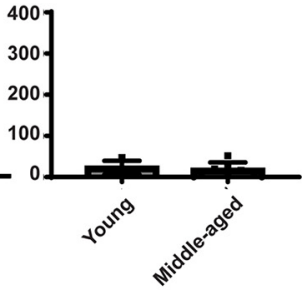

$72 \mathrm{~h}$

\section{Microglia}

\section{Peripheral leukocytes}

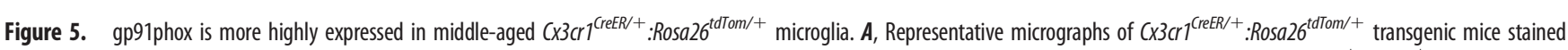
with antibodies against CD45 in middle-aged mice. High-magnification images were taken within lesioned white matter. Microglia $(\#)$ are double positive $\left(\mathrm{tdTom}{ }^{+}, \mathrm{CD}^{+} 5^{+}\right)$, and peripheral leukocytes $\left({ }^{*}\right)$ are single positive $\left(C D 45^{+}\right)$. Scale bars: high magnification, $50 \mu \mathrm{m}$; low magnification, $100 \mu \mathrm{m}$. B. Representative micrographs of coronal spinal cord sections from C $\times 3 \mathrm{cr} 7^{\text {reeRR/+ }}$ :Rosa2 $6^{\text {tdTom/+ }}$ mice stained with antibodies against gp91phox and CD45. A positive signal can be detected in young and middle-aged animals and in CNS macrophages and peripheral leukocytes. Scale bar, $50 \mu \mathrm{m}$. C, More gp91phox ${ }^{+}$signal spatially localizes with tdTom ${ }^{+}$signal in middle-aged mice relative to young at both 24 and $72 \mathrm{~h}$ following the injection of lysolecithin ( $24 \mathrm{~h}, p=0.0358 ; 72 \mathrm{~h}, p=0.0303)$. D, CD45 ${ }^{+}$signal from peripheral leukocytes displays low spatial localization with gp91phox $(24 \mathrm{~h}, p=0.6208 ; 72 \mathrm{~h}, p=0.6619)$. Each dot

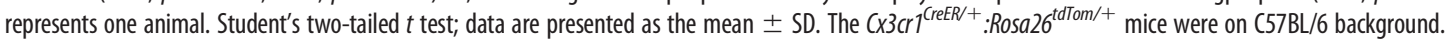

immunoreactivity for gp91phox in middle-aged animals (Fig. $4 B)$. Unlike the RNA changes, immunoreactivity for p67phox yielded no significant difference between the groups (Fig. 4D,E). Together, these data show that middle-aged lysolecithin-induced injury is associated with increased expression of the catalytic subunit of NADPH oxidase gp91phox and with elevated oxidative stress within the lesions at acute time points.

gp91phox is more highly expressed in middle-aged microglia Previous studies demonstrating gp91phox expression in traumatic models of injury and EAE (Kumar et al., 2013; Di Filippo et al., 2016; von Leden et al., 2017) were unable to differentiate between CNS-intrinsic microglia and monocyte-derived macrophages infiltrating into lesions from the periphery. We used a previously described genetic fate-mapping approach based on the expression of $\mathrm{CX}_{3} \mathrm{CR} 1$ in CNS-intrinsic microglia and the high turnover rate of monocytes to differentiate between the two cell types (Parkhurst et al., 2013; Plemel et al., 2020). Upon initial administration of tamoxifen, all $\mathrm{CX}_{3} \mathrm{CR} 1^{+}$populations recombine and express the tdTom reporter. Peripheral populations, however, are quickly replaced by non-tdTom-expressing progenitors, leaving self-renewing microglia and CNS border-associated macrophages as the sole expressors of tdTom. Allowing at least 4 weeks between 
A

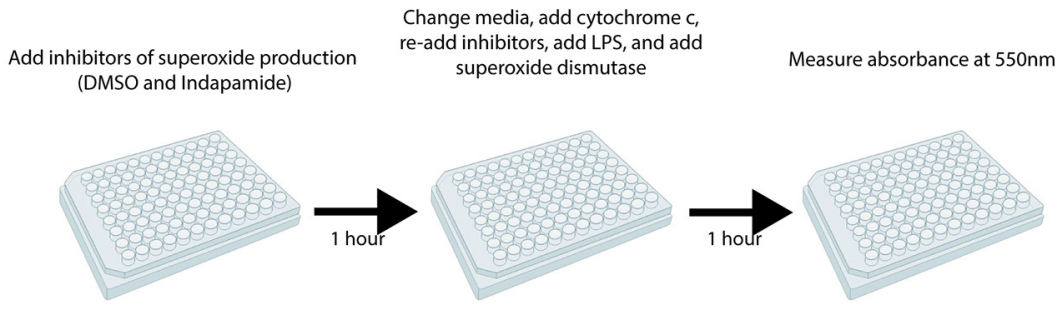

B

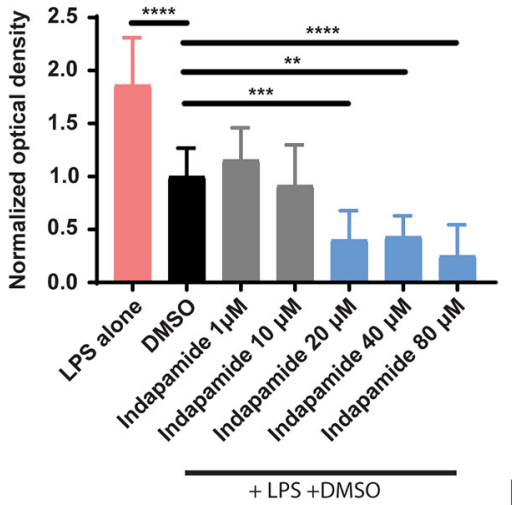

C

D

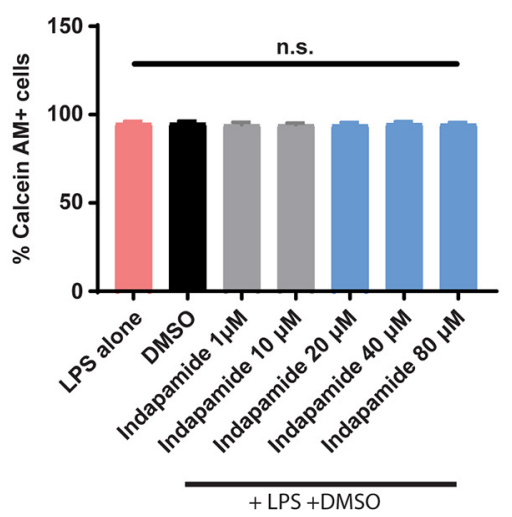

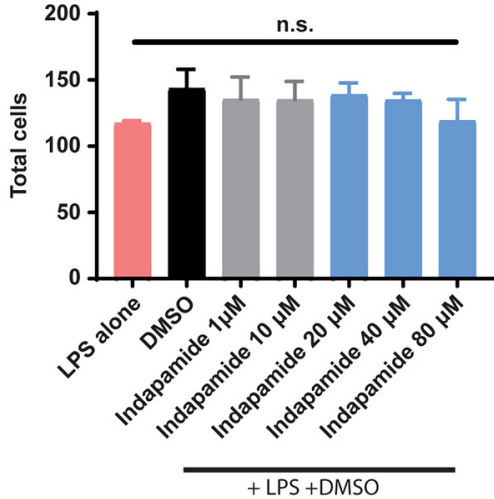

E

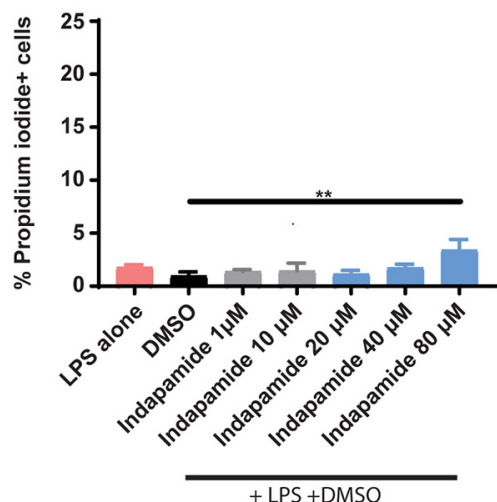

\section{$\mathbf{F}$}

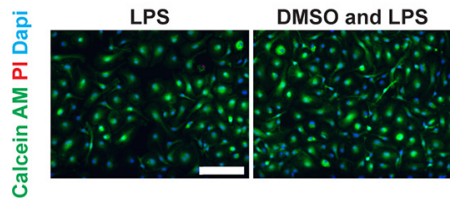

Indapamide $1 \mu \mathrm{M}$
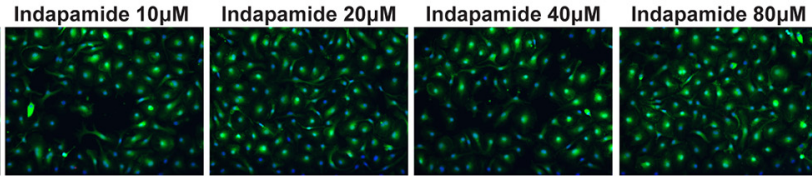

Figure 6. The generic medication indapamide reduces extracellular superoxide derived from CD1 microglia in vitro. $\boldsymbol{A}$, Schematic of extracellular superoxide measurement in microglia cultures. $\boldsymbol{B}$, Extracellular superoxide, measured by cytochrome c oxidation, significantly decreased with the addition of higher concentrations of indapamide to the media relative to the DMSO control (indapamide $1 \mu \mathrm{m}, p=0.8983$; indapamide $10 \mu \mathrm{m}, p=0.9954$; indapamide $20 \mu \mathrm{m}, p=0.003$; indapamide $40 \mu \mathrm{m}, p=0.0021$; indapamide $80 \mu \mathrm{m}, p \leq 0.0001$ ). C, Total number of cells (DAPI $^{+}$nuclei) was not different between conditions $(p=0.1425)$. Numbers based on 12 sites imaged per well. $\boldsymbol{D}$, Percentage of calcein $\mathrm{AM}^{+}$cells was not altered between conditions $(p=0.8592)$. $\boldsymbol{E}$, Percentage of propidium iodide-positive cells was not different between conditions until the highest concentration of indapamide (80 $\mu \mathrm{m})$ was used (indapamide $1 \mu \mathrm{m}$, $p=0.9584$; indapamide $10 \mu \mathrm{m}, p=0.9201$; indapamide $20 \mu \mathrm{m}=0.9995$; indapamide $40 \mu \mathrm{m}, p=0.5824$; indapamide $80 \mu \mathrm{m}, p=0.0010$ ). One-way ANOVA with Dunnett's correction for multiple comparisons. Data combined from multiple experiments using DMSO and LPS as a common internal control for each experiment. $\boldsymbol{F}$, Representative micrographs of cultured microglia stained with calcein AM (labels living cells), propidium iodide (labels dead/dying cells), and DAPI to stain all nuclei. Note that the indapamide groups contained DMSO and LPS. Images were captured with a $20 \times$ objective lens. Scale bar, $100 \mu \mathrm{m}$. Cells were from CD1 outbred mice as these were inexpensive compared with pregnant C57BL/6 mice to yield microglia cultures. ${ }^{* *} p<$ $0.01,{ }^{* * *} p<0.001,{ }^{* * *} p<0.0001$. n.s., not significant.

tamoxifen administration and lysolecithin surgery and using tdTom expression in combination with CD45, we were able to differentiate between microglia in the parenchyma $\left(\mathrm{CD} 45^{+} \mathrm{tdTom}^{+}\right)$ from spatially confined border-associated macrophages and monocyte-derived macrophages $\left(\mathrm{CD} 45^{+}\right.$tdTom $^{-}$; Fig. 5A). We stained tissue isolated from $\mathrm{CX}_{3} \mathrm{CR} 1^{\mathrm{CreER} /+}$ :tdTom mice 24 and $72 \mathrm{~h}$ after the injection of lysolecithin for gp91phox (Fig. 5B).
The majority of gp91phox immunoreactivity was restricted to tdTom $^{+}$cells (Fig. 5C,D). We observed significantly more gp91phox immunoreactivity associated with tdTom $^{+}$cells in middle-aged animals compared with young animals. These data suggest that microglia are the primary expressors of the elevated gp91phox and oxidative stress in the acute lesion of middle-aged mice. 
The generic medication indapamide reduces extracellular superoxide derived from microglia in vitro Microglia generate extracellular superoxide in a NADPH oxidase-dependent manner during respiratory burst (Wilkinson and Landreth, 2006; Moore and MacKenzie, 2009). Superoxide interacts with hydrogen peroxide to form the highly reactive hydroxyl radical. We measured extracellular superoxide generation from microglia cultured from CD1 neonatal mouse pups using a protocol based on the oxidation of cytochrome $c$ (Fig. 6A). We then tested the ability of indapamide, a generic antihypertensive CNS-penetrant medication that we previously described as a potent scavenger of the hydroxyl radical (Faissner et al., 2017), to reduce extracellular superoxide. In LPS-stimulated conditions where microglia production of superoxide can be reliably detected, the vehicle DMSO reduced the generation of superoxide. This is consistent with DMSO being reported to have antioxidant properties (Sanmartín-Suárez et al., 2011; Dludla et al., 2018). Indapamide (constituted in DMSO) significantly reduced extracellular superoxide at concentrations of $\geq 20 \mu \mathrm{M}$ relative to DMSO (Fig. $6 B$ ). Using cell viability assays, we determined that our results were not because of the toxicity of indapamide or DMSO (Fig. 6C-F).

Indapamide decreases lipid peroxidation, demyelination, and axon loss after lysolecithin injury in middle-aged mice Since age-exacerbated injury corresponds with elevated expression of ROS-producing NADPH oxidase and increased lipid peroxidation, we evaluated whether indapamide could decrease the age-associated elevation of myelin disruption and axon injury. In the first dosing regimen, middle-aged $\mathrm{C} 57 \mathrm{BL} / 6$ mice were injected intraperitoneally once per day with $20 \mathrm{mg} / \mathrm{kg}$ indapamide. Animals treated with indapamide or vehicle did not manifest any obvious outward signs of distress or weight loss, although no biological specimens such as serum or urine were measured for molecules to affirm safety. Treatment began $2 \mathrm{~h}$ after the injection of lysolecithin and continued for $3 \mathrm{~d}$. Mice were then killed (Fig. 7A). Spinal cord sections showed less malondialdehyde-positive immunoreactivity with indapamide treatment (Fig. $7 B, C$ ) and a smaller volume of myelin disruption in eriochrome cyanine-stained sections (Fig. $7 D, E$ ). Axonal loss, however, was not mitigated (Fig. $7 F, G$ ). In the second dosing regimen, treatment with $20 \mathrm{mg} / \mathrm{kg}$ indapamide began $3 \mathrm{~d}$ before lysolecithin in middleaged C57BL/6 mice (Fig. 8A). The pretreatment paradigm is clinically justifiable since MS demyelinating lesions can develop at any stage of a patient's disease course and the pretreatment would represent an attempt to affect a future event/relapse, mirroring the use of immunomodulatory treatment in MS. We also treated mice twice per day to maintain higher concentrations of indapamide in vivo.
At killing $72 \mathrm{~h}$ after lysolecithin administration, the expression of malondialdehyde was almost undetectable with the indapamide pretreatment (Fig. 8B,C) and lesion volume was significantly reduced (Fig. $8 D, E$ ). Axon loss was also decreased by indapamide pretreatment when evaluated either by the number of remaining $\mathrm{SMI} 312^{+}$profiles in a lesion, or in the proportion of axons lost when compared with the uninvolved white matter area (Fig. $8 \mathrm{~F}-\mathrm{H}$ ). Overall, the treatment of middle-aged C57BL/ 6 mice was associated with reduced indication of oxidative stress, fewer axons lost, and lower lesion volume.

\section{Discussion}

Age is associated with increased injury or poor recovery in MS, stroke, traumatic brain injury, and spinal cord injury (Sacco, 
A

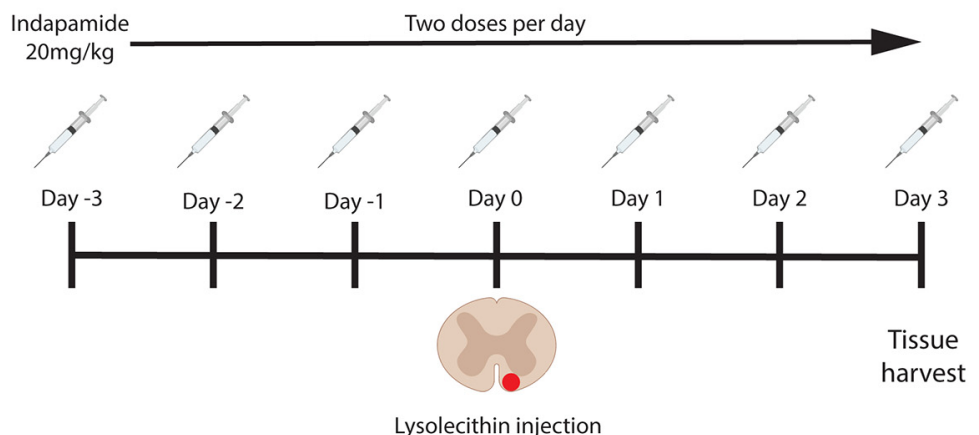

B

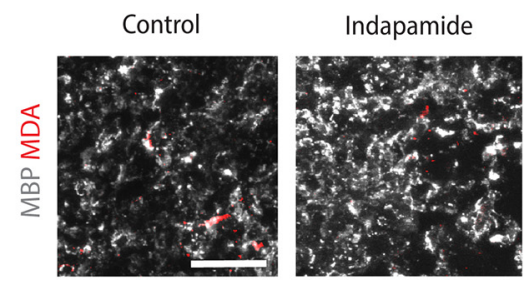

D
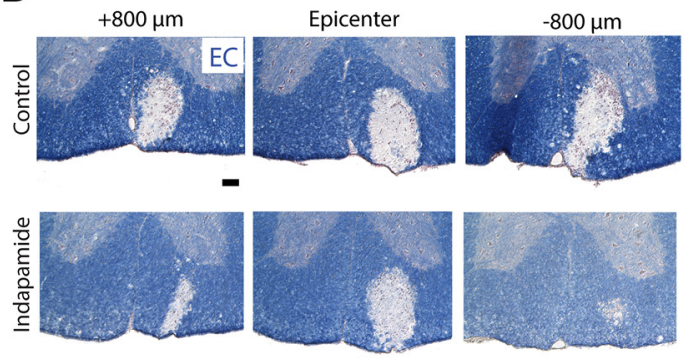

$\mathbf{F}$

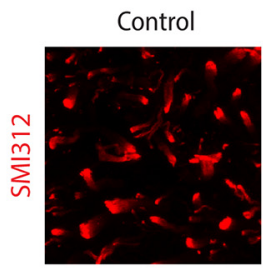

Indapamide

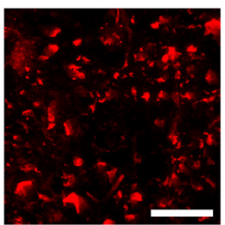

C

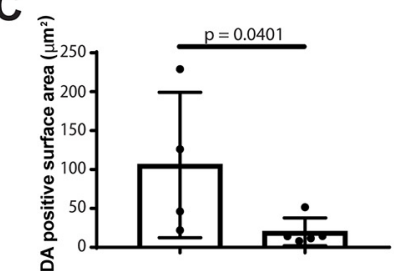

E

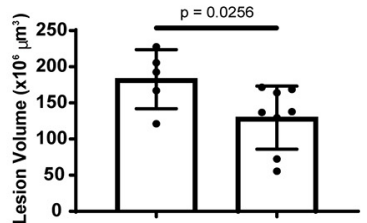

G

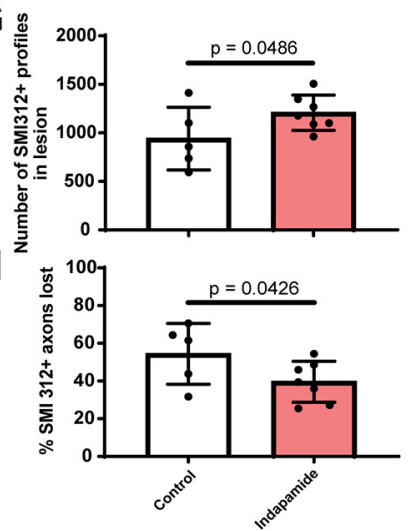

Figure 8. Indapamide pretreatment decreases lipid peroxidation, demyelination, and axon loss in middle-aged C57BL/6 mice. $A$, Indapamide $(20 \mathrm{mg} / \mathrm{kg})$ was injected intraperitoneally into middle-aged animals two times per day. Treatment started $3 \mathrm{~d}$ before the injection of lysolecithin into the ventrolateral white matter of the spinal cord and continued until tissue was harvested for analysis $3 \mathrm{~d}$ after. $\boldsymbol{B}$, Representative micrographs of middle-aged tissue isolated from mice treated with indapamide or DMSO control. Coronal spinal cord sections were stained with antibodies against MDA. Scale bar, $25 \mu \mathrm{m}$. $C$, Quantification of $\mathrm{MDA}^{+}$profiles in lesions revealed decreased lipid peroxidation in mice treated with indapamide. Each dot represents one animal. $\boldsymbol{D}$, Representative micrographs of coronal spinal cord sections stained with eriochrome cyanine to visualize lipids. Scale bar, $100 \mu \mathrm{m}$. $\boldsymbol{E}$, The volume of myelin disruption is decreased in middle-aged animals treated with indapamide. $\boldsymbol{F}$, Treated and control middle-aged tissue stained for SMI312. Scale bar, $50 \mu \mathrm{m}$. G, Quantification of SMI312 ${ }^{+}$ profiles in the middle of the lesion. Absolute $\mathrm{MMI}_{312}{ }^{+}$profiles is increased with indapamide treatment. $\boldsymbol{H}$, The proportion of axons lost relative to normal-appearing white matter (NAWM) is lower with treatment. $\boldsymbol{C}, \boldsymbol{E}, \boldsymbol{G}, \boldsymbol{H}$, Each dot represents one animal (Student's one-tailed $t$ test). Data are presented as the mean \pm SD.

1997; Dai, 2001; Michael and Shaughnessy, 2006; Marquez de la Plata, 2008; Goldschmidt et al., 2009). Increased lesion size and elevated tissue damage with age have also been demonstrated in animal models of traumatic injury (Siegenthaler et al., 2008; Kumar et al., 2013; von Leden et al., 2017). We are the first to comment on an elevated volume of acute myelin disruption in an animal model commonly used to study MS. The above studies, along with the data we have acquired in the lysolecithin model, implicate increased lesion volume and axon injury as general features of advancing age that span several injury models.

We note that the lysolecithin injection into the spinal cord has previously been reported to be axon sparing while producing demyelination (Huang et al., 2012). In our study, axonal loss as determined by immunoreactivity for phosphorylated neurofilaments (SMI312 antibody) was $\sim 40 \%$ and $60 \%$ in young and middle-aged mice, respectively, at day 3. Another group (El Waly et al., 2020) reported that lysolecithin produced a $56 \%$ loss of Thy1-GFP-detected axons by $2 \mathrm{~d}$ of administration into the spinal cord of 7- to 10-week-old mice. Clearly, the discrepancies between laboratories for axonal degeneration after lysolecithin administration requires resolution.

Experiments in traumatic brain and spinal cord injury suggest that the immune response to injury in aging animals is more pathologic. Microglia/macrophages in aged animals secrete more proinflammatory factors and ROS in response to injury (Kumamaru et al., 2012; Kumar et al., 2013; von Leden et al., 2017). NADPH oxidase, a significant producer of ROS in microglia/macrophages, has been implicated in MS lesions and these injury models. Aged immune cells in the CNS also have a decreased ability to adopt a regulatory phenotype (Miron et al., 2013). More proinflammatory factors, elevated oxidative stress, and a decreased propensity to adopt a regulatory phenotype skew the aging lesion environment in a direction more conducive to pathology than to repair. Aligning with a body of literature in models of CNS injury and EAE, our transcriptomic and immunohistochemical analyses highlight the importance of ROS production and gp91phox in microglia/ macrophages. We observed elevated lipid peroxidation in middle-aged $\mathrm{C} 57 \mathrm{BL} / 6$ tissue and increased expression of gp91phox in close spatial association with $\mathrm{CD} 45^{+}$ leukocytes. Oxidative stress can overwhelm endogenous antioxidant defenses and propagate tissue damage by irreversibly altering cellular macromolecules and inducing apoptosis. ROS production is elevated in the CNS of aged animals after peripheral injection of LPS (Qin et al., 2013). Also, oxidative stress, measured with dihydroethidium to indicate DNA oxidation, is increased in aged animals after spinal cord injury (Zhang et al., 2016; von Leden et al., 2017).

DNA and lipid peroxidation is observed in MS lesions and can be visualized using antibodies for oxidized DNA, oxidized phospholipids, or a byproduct of lipid oxidation, malondialdehyde (Haider et al., 2011). In MS tissue, oxidized phospholipid staining and malondialdehyde staining appear in spatial association with oligodendrocytes, myelin, acutely injured axons, 
neurons, astrocytes, and microglia/macrophages (Haider et al., 2011). We focused our study on malondialdehyde because lipid peroxidation affects structures (i.e., oligodendrocytes, myelin, and acutely injured axons) associated with age-exacerbated injury and would, in the context of lysolecithin, be a more sensitive measure of oxidative stress. We observed elevated malondialdehyde-positive staining in middle-aged C57BL/6 tissue. This staining occurred in close spatial association with structures labeled by MBP. Our findings demonstrating the spatial association of gp91phox with CD45 ${ }^{+}$leukocytes is supported by the previously mentioned studies in MS and other animal models.

Herein, we found how quickly after a myelin disrupting event the production of ROS and oxidative stress is exacerbated in the aging lesion-we observed increased NADPH oxidase staining $24 \mathrm{~h}$ after lysolecithin injection and elevated malondialdehyde-positive profiles at $72 \mathrm{~h}$. Furthermore, by using the $C x_{3} C r 1^{C r e E R /+}:$ Rosa $26^{\text {tdTom/+ }}$ line, we implicate microglia as the primary expressors of NADPH oxidase at acute time points after myelin disruption in the spinal cord. Increased NADPH oxidase expression and elevated oxidative stress this early after myelin disruption have important implications as the lesion develops, especially considering that we do not observe a synchronous increase in antioxidant enzymes. Oxidative damage is self-propagating, and the early phenotype of microglia may largely impact the highly plastic nature of monocytes and other immune cells entering from the periphery, skewing them to the immune environment already present in the CNS (Bennett et al., 2018).

We note that the $C x_{3} C r 1^{C r e E R /+}: R o s a 26^{t d T o m /+}$ line identified microglia and not monocyte-derived macrophages as the early source of elevated NADPH oxidase in aging mice after demyelination. Previous work done with this heterozygous line suggests that the maturation, development, and function of myeloid populations, including microglia, is not altered in mice lacking one copy of the endogenous CX3CR1 gene (Parkhurst et al., 2013). However, a more recent study reports that heterozygous CX3CR1 deficiency in microglia affects phagocytosis in an Alzheimer's disease mouse model (Hickman et al., 2019). Thus, the data from the $C x_{3} C r 1^{C r e E R /+}: R o s a 26^{t d T o m /+}$ line must be interpreted with caution.

Differential gene expression and IPA analysis of the young and middle-aged C57BL/6 transcriptome $72 \mathrm{~h}$ after lysolecithin suggested the prominent involvement of genes in addition to $C y b b$, notably Clec7a, CD74, Ccnb1, Mmp12, and Lbp. The Clec7a gene encodes for a member of the C-type lectin/C-type lectin-like domain superfamily. This receptor functions as a pattern recognition receptor, and Krasemann et al. (2017) have associated it with a neurodegenerative microglial phenotype. CD74 is a polypeptide involved in the formation and transport of MHC class II. It is the receptor for macrophage migration inhibitory factor (MIF) and plays a crucial role in the regulation of inflammation in EAE (Benedek et al., 2013). Blocking the interaction of MIF and CD74 decreases proinflammatory cytokine secretion in EAE (Benedek et al., 2013). CCNB1 is a regulatory protein involved in mitosis. This cyclin has been described only in the context of neuropathic pain following spinal cord injury. Its role in MS or other demyelinating disorders is unclear (Zhang and Yang, 2017). MMP12 is a matrix metalloproteinase whose knockout in EAE is associated with increased damage and elevated clinical disease scores relative to the wild-type control (Goncalves DaSilva and Yong, 2009). Lbp is involved in the innate immune response and may play a role in mediating the connection between the gut microbiota and autoimmunity in
MS (Escribano et al., 2017). Collectively, our data suggest an altered immune response in middle-aged animals that is more conducive of injury and less supportive of repair.

Our group previously conducted a systematic screen aimed at identifying orally available, well tolerated generic medications that target pathologic elements of progressive MS, including the alleviation of oxidative stress (Faissner et al., 2017). We identified several medications of potential utility, including indapamide, which had good evidence of blood-brain barrier permeability. In vitro, indapamide protected neurons from iron- and rotenonemediated toxicity and was a proficient scavenger of the hydroxyl radical (Faissner et al., 2017). Using similar concentrations of indapamide, we were able to show a reduction of superoxide derived from CD1 microglia. Indapamide has been identified as a free radical scavenger before. It, and its metabolite 5-OH indapamide, are effective scavengers of the superoxide anion and protect against damage associated with the highly reactive peroxyl radical (Vergely et al., 1998). Indapamide also alleviates tissue damage in models of myocardial ischemia/reperfusion and renal injury (Mouhieddine et al., 1993) and tissue injury in the kidney of rats with hypertension (Uehara et al., 1993). In our study, we have attributed the alleviation of tissue injury by indapamide in middle-aged animals to its antioxidant properties in the CNS, in particular the inhibition of NADPH oxidase activity in microglia. This causative relationship will need to be established in future experiments. Beyond free radical scavenging, indapamide has other properties that may have influenced our results. Indapamide is a diuretic and is currently prescribed as an antihypertensive agent because of this property. Perturbations in ion homeostasis and vascular permeability because of diuresis could contribute unknown mechanisms to the decreased myelin disruption and axon loss observed in our experiments. Further studies will more directly address the mechanism of indapamide action in the CNS.

In summary, our data show that a similar injury is more devastating to axons and myelin in middle-aged compared with young $\mathrm{C} 57 \mathrm{BL} / 6$ mice. Considering that age is a critical risk factor in the development of progressive MS, our results provide important implications for disease modification with advancing age, emphasizing a need for neuroprotection. We highlight indapamide as a generic, CNS-penetrant drug with antioxidant properties that alleviates aging-enhanced myelin disruption and axon loss. Our findings also have implications for the treatment of other neurodegenerative conditions where oxidative stress plays a role in pathology, including Alzheimer's, Huntington's, and Parkinson's disease.

\section{References}

Badger AM (1986) Enhanced superoxide production by rat alveolar macrophages stimulated in vitro with biological response modifiers. J Leukoc Biol 40:725-736.

Benedek G, Meza-Romero R, Andrew S, Leng L, Burrows GG, Bourdette D, Offner H, Bucala R, Vandenbark AA (2013) Partial MHC class II constructs inhibit MIF/CD74 binding and downstream effects. Eur J Immunol 43:1309-1321.

Bennett FC, Bennett ML, Yaqoob F, Mulinyawe SB, Grant GA, Hayden Gephart M, Plowey ED, Barres BA (2018) A Combination of ontogeny and CNS environment establishes microglial identity. Neuron 98:11701183.e8.

Bjartmar C, Wujek JR, Trapp BD (2003) Axonal loss in the pathology of MS: consequences for understanding the progressive phase of the disease. J Neurol Sci 206:165-171.

Confavreux C, Vukusic S (2006) Natural history of multiple sclerosis: a unifying concept. Brain 129:606-616. 
Dai LY (2001) Acute central cervical cord injury: the effect of age upon prognosis. Injury 32:195-199.

Di Filippo M, de Iure A, Giampà C, Chiasserini D, Tozzi A, Orvietani PL, Ghiglieri V, Tantucci M, Durante V, Quiroga-Varela A, Mancini A, Costa C, Sarchielli P, Fusco FR, Calabresi P (2016) Persistent activation of microglia and NADPH drive hippocampal dysfunction in experimental multiple sclerosis. Sci Rep 6:20926.

Dludla PV, Jack B, Viraragavan A, Pheiffer C, Johnson R, Louw J, Muller CJF (2018) A dose-dependent effect of dimethyl sulfoxide on lipid content, cell viability and oxidative stress in 3T3-L1 adipocytes. Toxicol Rep 5:1014-1020.

El Waly B, Buttigieg E, Karakus C, Brustlein SD, Debarbieux F (2020) Longitudinal intravital microscopy reveals axon degeneration concomitant with inflammatory cell infiltration in an LPC model of demyelination. Front Cell Neurosci 14:165.

Escribano BM, Medina-Fernández FJ, Aguilar-Luque M, Agüera E, Feijoo M, Garcia-Maceira FI, Lillo R, Vieyra-Reyes P, Giraldo AI, Luque E, Drucker-Colín R, Túnez I (2017) Lipopolysaccharide binding protein and oxidative stress in a multiple sclerosis model. Neurotherapeutics 14:199-211.

Faissner S, Mishra M, Kaushik DK, Wang J, Fan Y, Silva C, Rauw G, Metz L, Koch M, Yong VW (2017) Systematic screening of generic drugs for progressive multiple sclerosis identifies clomipramine as a promising therapeutic. Nat Commun 8:1990.

Fenn AM, Hall JCE, Gensel JC, Popovich PG, Godbout JP (2014) IL-4 signaling drives a unique arginase $\mathrm{e}^{+} / \mathrm{IL}-1 \beta^{+}$microglia phenotype and recruits macrophages to the inflammatory CNS: consequences of age-related deficits in IL-4R $\alpha$ after traumatic spinal cord injury. J Neurosci 34:89048917.

Fischer MT, Sharma R, Lim JL, Haider L, Frischer JM, Drexhage J, Mahad D, Bradl M, van Horssen J, Lassmann H (2012) NADPH oxidase expression in active multiple sclerosis lesions in relation to oxidative tissue damage and mitochondrial injury. Brain 135:886-899.

Goldschmidt T, Antel J, König FB, Brück W, Kuhlmann T (2009) Remyelination capacity of the MS brain decreases with disease chronicity. Neurology 72:1914-1921.

Goncalves DaSilva A, Yong VW (2009) Matrix metalloproteinase-12 deficiency worsens relapsing-remitting experimental autoimmune encephalomyelitis in association with cytokine and chemokine dysregulation. Am J Pathol 174:898-909.

Haider L, Fischer MT, Frischer JM, Bauer J, Höftberger R, Botond G, Esterbauer H, Binder CJ, Witztum JL, Lassmann H (2011) Oxidative damage in multiple sclerosis lesions. Brain 134:1914-1924.

Hampton DW, Innes N, Merkler D, Zhao C, Franklin RJM, Chandran S (2012) Focal immune-mediated white matter demyelination reveals an age-associated increase in axonal vulnerability and decreased remyelination efficiency. Am J Pathol 180:1897-1905.

Hickman SE, Allison EK, Coleman U, Kingery-Gallagher ND, E, Khoury J (2019) Heterozygous CX3CR1 deficiency in microglia restores neuronal $\beta$-amyloid clearance pathway and slows progression of Alzheimer's likedisease in PS1-APP mice. Frontiers Immunol 10:2780.

Huang JK, Ferrari CC, de Castro GM, Lafont D, Zhao C, Zaratin P, Pouly S, Greco B, Franklin RJM (2012) Accelerated axonal loss following acute CNS demyelination in mice lacking protein tyrosine phosphatase receptor type Z. Am J Pathol 181:1518-1523.

Irvine K-A, Blakemore WF (2006) Age increases axon loss associated with primary demyelination in cuprizone-induced demyelination in C57BL/6 mice. J Neuroimmunol 175:69-76.

Keren-Shaul H, Spinrad A, Weiner A, Matcovitch-Natan O, Dvir-Szternfeld R, Ulland TK, David E, Baruch K, Lara-Astaiso D, Toth B, Itzkovitz S, Colonna M, Schwartz M, Amit I (2017) A unique microglia type associated with restricting development of Alzheimer's disease. Cell 169:12761290.e17.

Koch M, Kingwell E, Rieckmann P, Tremlett H (2009) The natural history of primary progressive multiple sclerosis. Neurology 73:1996-2002.

Kotter MR, Li W-W, Zhao C, Franklin RJM (2006) Myelin impairs CNS remyelination by inhibiting oligodendrocyte precursor cell differentiation. J Neurosci 26:328-332.

Kozinska J, Sawicka KM, Zadrozniak A, Wojda E, Andres-Mach M, DudraJastrzebska M, Luszczki JJ (2009) Indapamide enhances the protective action of carbamazepine, phenobarbital, and valproate against maximal electroshock-induced seizures in mice. Adv Med Sci 54:66-74.
Krasemann S, Madore C, Cialic R, Baufeld C, Calcagno N, El Fatimy R, Beckers L, O'Loughlin E, Xu Y, Fanek Z, Greco DJ, Smith ST, Tweet G, Humulock Z, Zrzavy T, Conde-Sanroman P, Gacias M, Weng Z, Chen H, Tjon E, et al. (2017) The TREM2-APOE pathway drives the transcriptional phenotype of dysfunctional microglia in neurodegenerative diseases. Immunity 47:566-581.e9.

Kumamaru H, Saiwai H, Ohkawa Y, Yamada H, Iwamoto Y, Okada S (2012) Age-related differences in cellular and molecular profiles of inflammatory responses after spinal cord injury. J Cell Physiol 227:1335-1346.

Kumar A, Stoica BA, Sabirzhanov B, Burns MP, Faden AI, Loane DJ (2013) Traumatic brain injury in aged animals increases lesion size and chronically alters microglial/macrophage classical and alternative activation states. Neurobiol Aging 34:1397-1411.

Marcos R, Monteiro RA, Rocha E (2012) The use of design-based stereology to evaluate volumes and numbers in the liver: a review with practical guidelines. J Anat 220:303-317.

Marquez de la Plata CD, Hart T, Hammond FM, Frol AB, Hudak A, Harper CR, O’Neil-Pirozzi TM, Whyte J, Carlile M, Diaz-Arrastia R (2008) Impact of age on long-term recovery from traumatic brain injury. Arch Phys Med Rehabil 89:896-903.

Michael KM, Shaughnessy M (2006) Stroke prevention and management in older adults. J Cardiovasc Nurs 21:S21-S26.

Milner R, Ffrench-Constant C (1994) A developmental analysis of oligodendroglial integrins in primary cells: changes in alpha v-associated beta subunits during differentiation. Dev Camb Engl 120:3497-3506.

Miron VE, Boyd A, Zhao J-W, Yuen TJ, Ruckh JM, Shadrach JL, van Wijngaarden P, Wagers AJ, Williams A, Franklin RJM, Ffrench-Constant C (2013) M2 microglia and macrophages drive oligodendrocyte differentiation during CNS remyelination. Nat Neurosci 16:1211-1218.

Moore SF, MacKenzie AB (2009) NADPH oxidase NOX2 mediates rapid cellular oxidation following ATP stimulation of endotoxin-primed macrophages. J Immunol 183:3302-3308.

Mouhieddine S, Tresallet N, Boucher F, de Leiris J (1993) Ultrastructural basis of the free-radical scavenging effect of indapamide in experimental myocardial ischemia and reperfusion. J Cardiovasc Pharmacol 22:S47S52.

Nair AB, Jacob S (2016) A simple practice guide for dose conversion between animals and human. J Basic Clin Pharm 7:27-31.

Njie EG, Boelen E, Stassen FR, Steinbusch HWM, Borchelt DR, Streit WJ (2012) Ex vivo cultures of microglia from young and aged rodent brain reveal age-related changes in microglial function. Neurobiol Aging 33:195.e1-12.

O’Neil SM, Witcher KG, McKim DB, Godbout JP (2018) Forced turnover of aged microglia induces an intermediate phenotype but does not rebalance CNS environmental cues driving priming to immune challenge. Acta Neuropathol Commun 6:129.

Parkhurst CN, Yang G, Ninan I, Savas JN, Yates JR, Lafaille JJ, Hempstead BL, Littman DR, Gan W-B (2013) Microglia promote learning-dependent synapse formation through brain-derived neurotrophic factor. Cell 155:1596-1609.

Perry VH, Holmes C (2014) Microglial priming in neurodegenerative disease. Nat Rev Neurol 10:217-224.

Plemel JR, Stratton JA, Michaels NJ, Rawji KS, Zhang E, Sinha S, Baaklini CS, Dong Y, Ho M, Thorburn K, Friedman TN, Jawad S, Silva C, Caprariello AV, Hoghooghi V, Yue J, Jaffer A, Lee K, Kerr BJ, Midha R, et al. (2020) Microglia response following acute demyelination is heterogeneous and limits infiltrating macrophage dispersion. Sci Adv 6:eaay6324.

Plemel JR, Michaels NJ, Weishaupt N, Caprariello AV, Keough MB, Rogers JA, Yukseloglu A, Lim J, Patel VV, Rawji KS, Jensen SK, Teo W, Heyne B, Whitehead SN, Stys PK, Yong VW (2018) Mechanisms of lysophosphatidylcholine-induced demyelination: a primary lipid disrupting myelinopathy. Glia 66:327-347.

Qin L, Liu Y, Hong J-S, Crews FT (2013) NADPH oxidase and aging drive microglial activation, oxidative stress, and dopaminergic neurodegeneration following systemic LPS administration. Glia 61:855-868.

Rawji KS, Mishra MK, Michaels NJ, Rivest S, Stys PK, Yong VW (2016) Immunosenescence of microglia and macrophages: impact on the ageing central nervous system. Brain 139:653-661.

Reich DS, Lucchinetti CF, Calabresi PA (2018) Multiple sclerosis. N Engl J Med 378:169-180. 
Ruckh JM, Zhao J-W, Shadrach JL, van Wijngaarden P, Rao TN, Wagers AJ, Franklin RJM (2012) Rejuvenation of regeneration in the aging central nervous system. Cell Stem Cell 10:96-103.

Sacco RL (1997) Risk factors, outcomes, and stroke subtypes for ischemic stroke. Neurology 49:S39-S44.

Sanmartín-Suárez C, Soto-Otero R, Sánchez-Sellero I, Méndez-Álvarez E (2011) Antioxidant properties of dimethyl sulfoxide and its viability as a solvent in the evaluation of neuroprotective antioxidants. J Pharmacol Toxicol Methods 63:209-215.

Siegenthaler MM, Berchtold NC, Cotman CW, Keirstead HS (2008) Voluntary running attenuates age-related deficits following SCI. Exp Neurol 210:207-216.

Tutuncu M, Tang J, Zeid NA, Kale N, Crusan DJ, Atkinson EJ, Siva A, Pittock SJ, Pirko I, Keegan BM, Lucchinetti CF, Noseworthy JH, Rodriguez M, Weinshenker BG, Kantarci OH (2013) Onset of progressive phase is an age dependent clinical milestone in multiple sclerosis. Mult Scler 19:188-198.

Uehara Y, Kawabata Y, Shirahase H, Wada K, Hashizume Y, Morishita S, Numabe A, Iwai J (1993) Oxygen radical scavengers and renal protection by indapamide diuretic in salt-induced hypertension of Dahl strain rats. J Cardiovasc Pharmacol 22:S42-S46.
Vergely C, Walker MK, Zeller M, Rademakers JR, Maupoil V, Schiavi P, Guez D, Rochette L (1998) Antioxidant properties of indapamide, 5-OH indapamide and hydrochlorothiazide evaluated by oxygen-radical absorbing capacity and electron paramagnetic resonance. Mol Cell Biochem 178:151-155.

von Leden RE, Khayrullina G, Moritz KE, Byrnes KR (2017) Age exacerbates microglial activation, oxidative stress, inflammatory and NOX2 gene expression, and delays functional recovery in a middle-aged rodent model of spinal cord injury. J Neuroinflammation 14:161.

Wilkinson BL, Landreth GE (2006) The microglial NADPH oxidase complex as a source of oxidative stress in Alzheimer's disease. J Neuroinflammation 3:30

Zaluska K, Kondrat-Wroble MS, Luszczki JJ (2018) Comparison of the anticonvulsant potency of various diuretic drugs in the maximal electroshock-induced seizure threshold test in mice. Adv Clin Exp Med 27: 609-613.

Zhang B, Bailey WM, McVicar AL, Gensel JC (2016) Age increases reactive oxygen species production in macrophages and potentiates oxidative damage after spinal cord injury. Neurobiol Aging 47:157-167.

Zhang G, Yang P (2017) Bioinformatics genes and pathway analysis for chronic neuropathic pain after spinal cord injury. Biomed Res Int 2017:6423021 